\title{
Beyond ribose and phosphate: Selected nucleic acid modifications for structure-function investigations and therapeutic applications
}

\author{
Christopher Liczner ${ }^{1}$, Kieran Duke ${ }^{1}$, Gabrielle Juneau ${ }^{1}$, Martin Egli² \\ and Christopher J. Wilds ${ }^{* 1}$
}

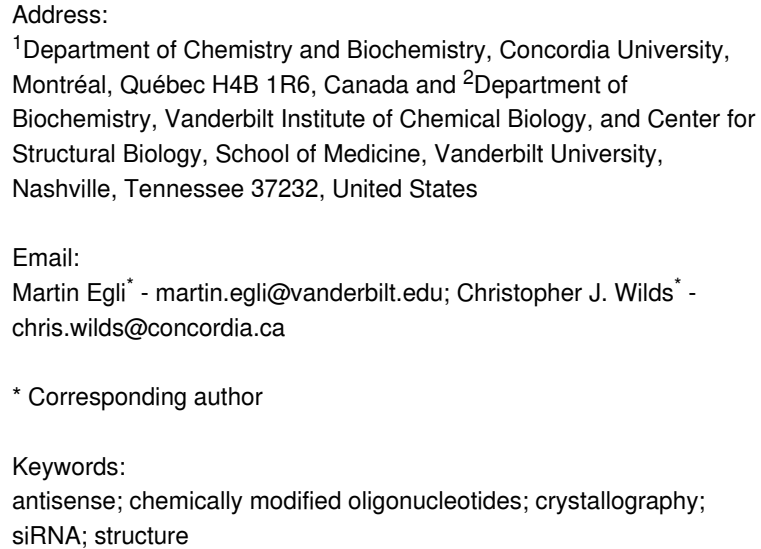

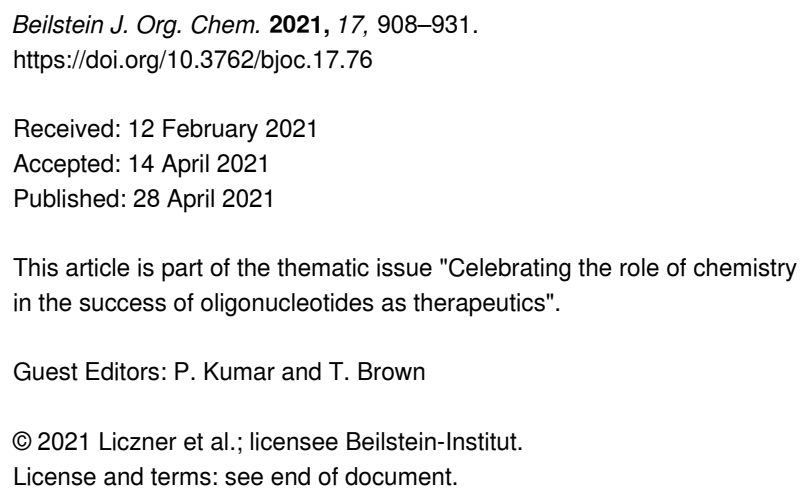

\begin{abstract}
Over the past 25 years, the acceleration of achievements in the development of oligonucleotide-based therapeutics has resulted in numerous new drugs making it to the market for the treatment of various diseases. Oligonucleotides with alterations to their scaffold, prepared with modified nucleosides and solid-phase synthesis, have yielded molecules with interesting biophysical properties that bind to their targets and are tolerated by the cellular machinery to elicit a therapeutic outcome. Structural techniques, such as crystallography, have provided insights to rationalize numerous properties including binding affinity, nuclease stability, and trends observed in the gene silencing. In this review, we discuss the chemistry, biophysical, and structural properties of a number of chemically modified oligonucleotides that have been explored for gene silencing.
\end{abstract}

\section{Introduction}

The natural nucleic acids sugar-phosphate backbone comes in two flavors, 2'-deoxyribose in DNA and ribose in RNA. However, this relative simplicity combined with the five natural bases, adenine $(A)$, cytosine $(C)$, guanine $(G)$, thymine $(T)$ and uracil (U, in RNA) belies the fact that both DNA and
RNA are decorated with chemical modifications. For a catalogue of natural modifications in DNA, see https:// dnamod.hoffmanlab.org/ [1], and in RNA, see https:// iimcb.genesilico.pl/modomics/ [2]. In DNA, base modifications are much more common than those in the backbone and play a 
central role in epigenetics, such as, for example, the 'fifth base' 5-methylcytosine (5mC) [3]. In the backbone, chemical modification appears to be limited to the phosphorothioate $R \mathrm{p}$-stereoisomer ( $R$ p-PS, i.e., phosphate with one of the non-bridging oxygens replaced by sulfur) in bacterial genomes, where it may serve a protective role against nucleases [4] and its loss results in genomic instability [5]. There are over a hundred known base modifications in RNA and the Rp-PS backbone modification occurs in ribosomal RNA (rRNA) of both pro- and eukaryotes [6]. A very common natural modification that concerns the ribose moiety is $2^{\prime}-O$-methylation $\left(2^{\prime}-O \mathrm{Me}\right) .2^{\prime}-O \mathrm{Me}$ nucleotides are scattered throughout all types of RNA, including mRNA, tRNA, rRNA, snRNA, snoRNA, miRNA and viral RNA [7-9]. Moreover, the modification occurs irrespective of the nature of the base and is therefore also referred to as $\mathrm{Nm}$ ( $\mathrm{N}=\mathrm{A}, \mathrm{C}, \mathrm{G}, 5 \mathrm{mU}, \mathrm{U}, \psi \mathrm{U}$, I, etc.) [10].

The specific role(s) an individual modification plays is often not known, but we can surmise involvements in transcription, translation, replication, splicing and other fundamental processes in biological information transfer. More specifically, they can affect chemical and thermodynamic stability, folding, secondary and tertiary structure, activity and interactions between nucleic acids, proteins and receptors. Particularly, as far as improving metabolic stability, pairing properties (RNA affinity), protein binding and transport/cellular uptake are concerned, chemical modifications are a prerequisite for the discovery and development of oligonucleotide therapeutics [11-15]. Thus, the natural PS and 2'-OMe backbone modifications provide improved resistance to degradation by exo- and endonucleases and they both affect protein binding [16,17]. Eight of the now approved 13 oligonucleotide drugs feature the PS modification in the backbone and all four approved siRNA therapeutics: ONPATTRO $^{\circledR}$ (patisiran, 2018), GIVLAARI ${ }^{\circledR}$ (givosiran, 2019), OXLUMO ${ }^{\circledR}$ (lumasiran, 2020) and LEQVIO ${ }^{\circledR}$ (inclisiran, 2020) have 2'-OMe modifications [18-21] (https:// www.oligotherapeutics.org/20th-anniversary-of-rna-interference-in-mammalian-cells/). Interestingly, both 2'-OMe [22] and PS [23] date back to the 1960s and constitute the earliest modifications reported by chemists along with the synthesis of 2'-deoxy-2'-fluoro-nucleosides (FRNA) [24].

The negatively charged phosphodiester linkages in the backbones of DNA and RNA are of fundamental importance for reactivity, stability, conformation and hydration [25,26]. The sugar moieties in DNA and RNA determine the shape of the double helix, i.e., the facile flip between the $\mathrm{C} 2$ '-endo (B-form DNA) and C3'-endo (A-form DNA) puckers by deoxyribose and the shift toward the $\mathrm{C} 3$ '-endo pucker due to the presence of the 2 '-OH in RNA [27,28]. As well, the seemingly small difference of a single hydroxy group between the sugars in DNA and
RNA is at the origin of the vastly expanded fold [29-32] and functional spaces of RNA [33-39]. Perhaps less known is the fact that the sugar moiety in the backbone of a nucleic acid determines the base pairing priorities. For example, in DNA G:C > A:T whereas in homo-DNA (2',3'- $\beta$-D-dideoxyglucopyranose nucleic acid) $\mathrm{G}: \mathrm{C}>\mathrm{A}: \mathrm{A} \approx \mathrm{G}: \mathrm{G}>\mathrm{A}: \mathrm{T}$ (reverse Hoogsteen $A: A$ and $G: G$ pairs) ([40] and cited references). Messenger RNA is the target of both the antisense and RNAi strategies to interfere with biological information transfer prior to production of proteins, enzymes and receptors that may be inhibited by small-molecule and antibody therapeutics. However, native RNA oligonucleotides do not possess sufficient metabolic stability for in vivo applications. Therefore, chemical modification is absolutely essential to re-engineer RNA into a therapeutic tool [15].

The chemical make-up of RNA, i.e., the ribose-phosphate backbone, has inspired countless strategies to chemically modify either the sugar [12,41-44], or the phosphate (e.g., amide-RNA [45]), or both $[46,47]$. In addition, the ribose has been replaced with alternative sugar moieties, such as a tetrose ( $\mathrm{L}-\alpha$-threofuranose, TNA [48]), and hexoses (e.g., hexitol, HNA [49]; altritol AtNA [50]; xylol XyNA [51]), or cyclohexene (CeNA [52]), a morpholino moiety (PMO [53]), and an acyclic, chiral glycol linker (GNA [54]), to generate so-called xeno nucleic acids (XNAs [55,56]). In arguably the most radical alternative nucleic acid pairing system, peptide nucleic acid (PNA), the sugarphosphate backbone is replaced by an amide-based, neutral and achiral scaffold that allows cross-pairing with both DNA and RNA as well as formation of double- and triple-stranded species [57]. Despite this growing universe of modifications, 2'-modifications, such as the original $2^{\prime}-O \mathrm{Me}, 2^{\prime}-O$-(2-methoxyethyl) (MOE [58,59]), and locked nucleic acid (LNA [44,60]) as well as the FRNA analogue [61-63] along with the phosphorothioates, will likely remain critical for the development of new oligonucleotide-based therapeutics. In the present review, we will summarize the properties of selected backbone modifications (Figure 1) and discuss investigations regarding their structure and function and, if applicable, their importance for therapeutic applications.

\section{Review}

\section{Internucleotide linkage modifications $\mathrm{N} 3^{\prime} \rightarrow$ P5' phosphoramidate}

The N3' $\rightarrow$ P5' phosphoramidate DNA (3'-NP DNA) contains a negatively charged internucleotide linkage, but one of the bridging oxygens is replaced by a nitrogen (Figure 1A). The $3^{\prime}$-NP linkage is generated during solid-phase synthesis where the incoming protected 5'-DMT-3'-aminonucleoside couples to the $5^{\prime}-\mathrm{H}$-phosphonate in the presence of a base (Scheme 1) [64]. 


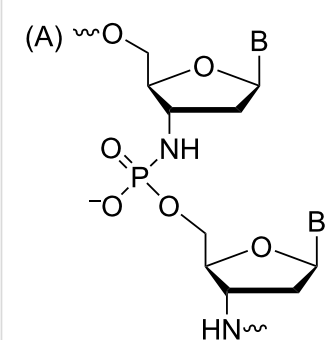

(F)

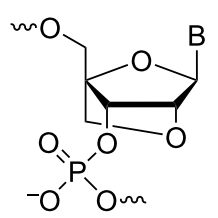

(B)

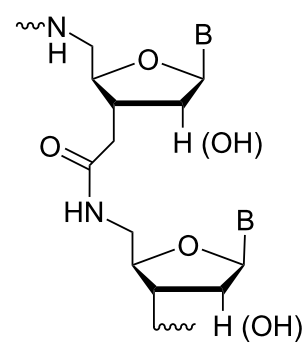

(C)

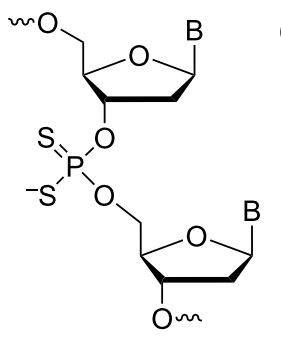

(D)<smiles>[B]C[C@@H](COC)OP(=O)(OC)O[C@H](C[B])OC</smiles>

(E)<smiles>[R]C1[C@@H]([2H])O[C@H](COC)[C@@H]1OP(=O)(OC)OC</smiles>

(G)

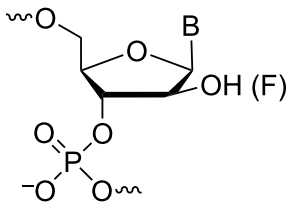

(H)

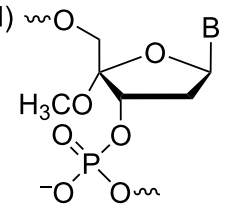<smiles>[B]C1COC(COC)C(OP(=O)([O-])O[Na])C1F</smiles>

$(\mathrm{J})$<smiles>C=C/C(=C(/C)F)C1OC(COC)[C@H](OP(=O)(OC)OC)[C@H]1O</smiles>

Figure 1: Structures of the chemically modified oligonucleotides (A) N3' $\rightarrow$ P5' phosphoramidate linkage, (B) amide (AM1) linkage, (C) phosphorodithioate (PS2), (D) glycol nucleic acid ( $R$-isomer), (E) 2'-O-alkyl modifications ( $\mathrm{R}=-\mathrm{CH}_{3},-\mathrm{CH}_{2} \mathrm{CH}_{2} \mathrm{OCH}$ ), (F) locked nucleic acids (LNA)/bridged nucleic acids (BNA), (G) arabinose (ANA) and arabinofluoro (FANA) nucleic acids, (H) C4'-modified nucleic acids, (I) 3'-fluorohexitol nucleic acid, (J) ribo-difluorotoluyl-modified nucleic acid.

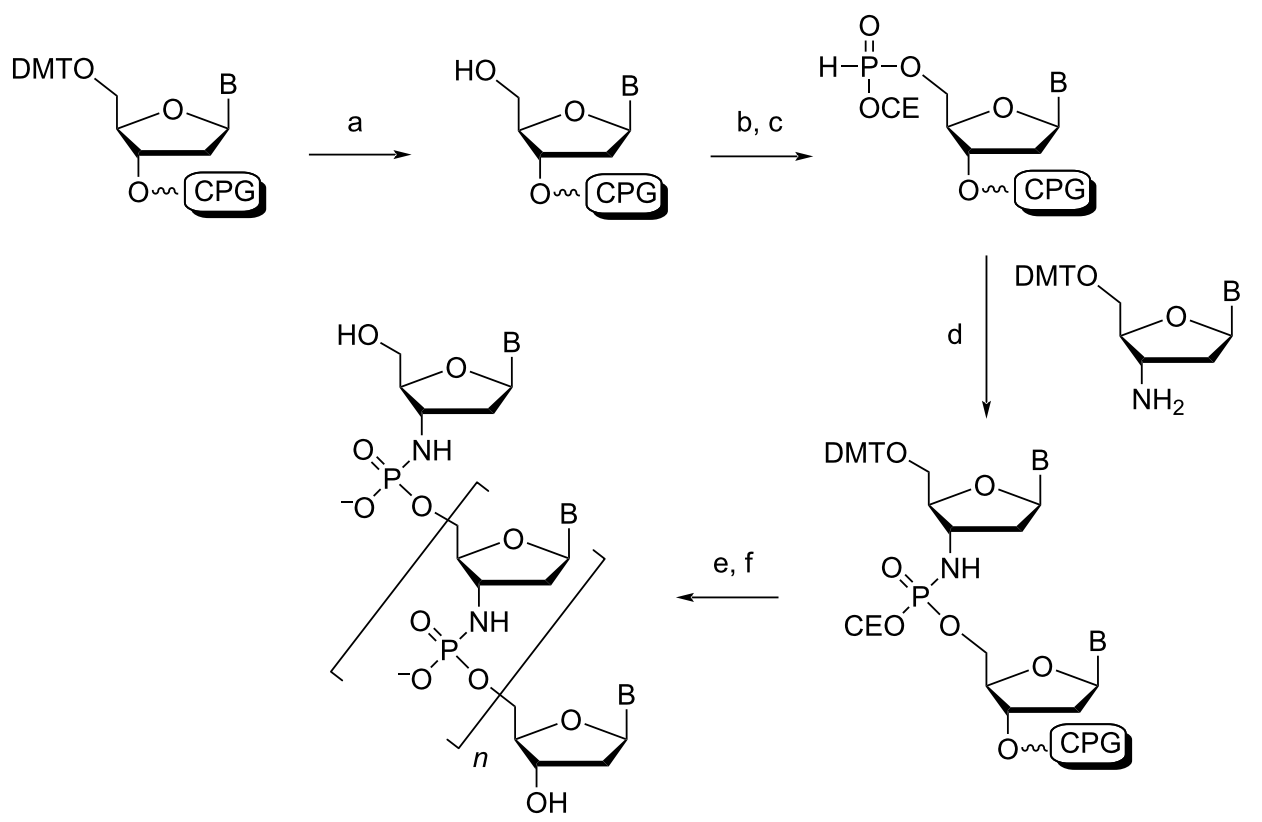

Scheme 1: Synthesis of a N3' $\rightarrow \mathrm{P}^{\prime}$ ' phosphoramidate linkage by solid-phase synthesis. (a) dichloroacetic acid; (b) $\mathrm{CIP}(\mathrm{NiPr} 2)(\mathrm{OCE})$; (c) tetrazole/ water; (d) triethylamine/carbon tetrachloride; (e) repeat steps a-d; (f) detritylate then deprotect with $\mathrm{NH}_{3}$. DMT = dimethoxytrityl, $\mathrm{CPG}=\mathrm{succinyl}-$ linked long chain alkylamine controlled pore glass solid support, $\mathrm{CE}=2$-cyanoethyl. Adapted from [64].

In comparison with natural phosphodiester oligonucleotides, these modified oligonucleotides display improved nuclease resistance and an enhanced duplex thermal stability of 2.3-2.6 ${ }^{\circ} \mathrm{C}$ per linkage independent of nucleotide sequence and base composition [65]. The presence of alternating phosphodiester and phosphoramidate linkages within an oligonucleotide resulted in improved binding to RNA relative to DNA. Homopyrimidine 3'-NP DNA forms a stable triplex at neutral $\mathrm{pH}$ with double-stranded DNA and RNA [64-66].
These attributes, nuclease stability, and hybridization to single and double stranded nucleic acid targets have led to studies to investigate 3'-NP DNA for antisense and antigene purposes. For example, as an antisense agent in the treatment of human leukemia [67], as an inhibitor of transcription elongation targeted to proviral HIV DNA [68], and as a triplex-forming oligonucleotide that selectively binds a sequence within the chromatin structure of cell nuclei [69]. Remarkably, 3'-NP DNA can also act as an RNA mimic in interactions with binding pro- 
teins despite lacking a ribose moiety, making them useful nuclease-resistant probes for studying RNA-protein interactions [70].

To better elucidate the structural features of 3'-NP DNA responsible for this enhanced selective binding and stability, the Egli group determined the crystal structure of the fully modified 3'-NP DNA duplex with the sequence 5'-d(CnpGnpCnpGnpAnpAnpTnpTnpCnpGnpCnpG)-3' at $2 \AA$ resolution [71]. It was found that the overall duplex structure adopted by 3'-NP DNA resembles that of an RNA-like A-form double helix. The deoxyribose ring of phosphoramidate DNA is locked in a northern (C3'-endo) conformation due to the decreased gauche effect between 4'-O and the 3'-N compared to the 4'-O and 3'-O interactions in DNA. The 3'-amino moieties in the structure's backbone were found to coordinate a larger amount of water molecules, on both the backbone and at groove sites. This increased hydration, as well as the configuration of the 3 -amino group enables the hydrogen atom to orient towards anions (chloride) in the vicinity and the 3'-nitrogen lone pair engages in a lp $\rightarrow \sigma^{*}$ anomeric effect with the antibonding orbital from the adjacent P-O5' bond (Figure 2A). This conjugation is surmised to cause considerably increased rigidity of the phosphoramidate sugar-phosphate backbone relative to native phosphodiester oligomers. This N-type sugar puckering and increased hydration of the sugar phosphate backbone could also account for the triplex-favoring properties of this modification [72].

\section{Amide}

While many amide backbone oligonucleotide variants exist, the focus of this review will be on the AM1-type shown in Figure 1B, as this is the most studied and therapeutically promising modification of its class (a summary of other amide variations can be found elsewhere $[74,75])$. The strategy used to incorporate this modification into DNA or RNA has been to first synthesize the nucleoside dimer phosphoramidite with the appropriate amide linkage, which can then be introduced into the strand by solid-phase synthesis. These dimers are synthesized by using an amide coupling reagent to condense a 3 '-carboxylic acid nucleoside with a 5'-amine nucleoside, where the necessary protecting groups are present on the nucleobase and sugar moieties [76,77].

Unlike the phosphodiester linkage of natural DNA, the AM1 modification is an example of a non-ionic backbone. The crystal structure of a 13-mer RNA duplex with a single central AM1 modification revealed that this modification is accommodated in an $\mathrm{A}^{\prime}$-form duplex [75]. Interestingly, an unconventional $\mathrm{C}-\mathrm{H}$... O hydrogen bond was observed between the amide's carbonyl oxygen and the nearby uracil C6-H6. The thermal stability of this modified duplex was, however, quite similar to native RNA. Typically, there is a decrease of $0.2-0.8^{\circ} \mathrm{C}$ in the thermal stability of RNA/DNA hybrid duplexes for each AM1 modification $[11,78]$. NMR structural studies have shown that the AM1 modification is well tolerated in an RNA duplex, with

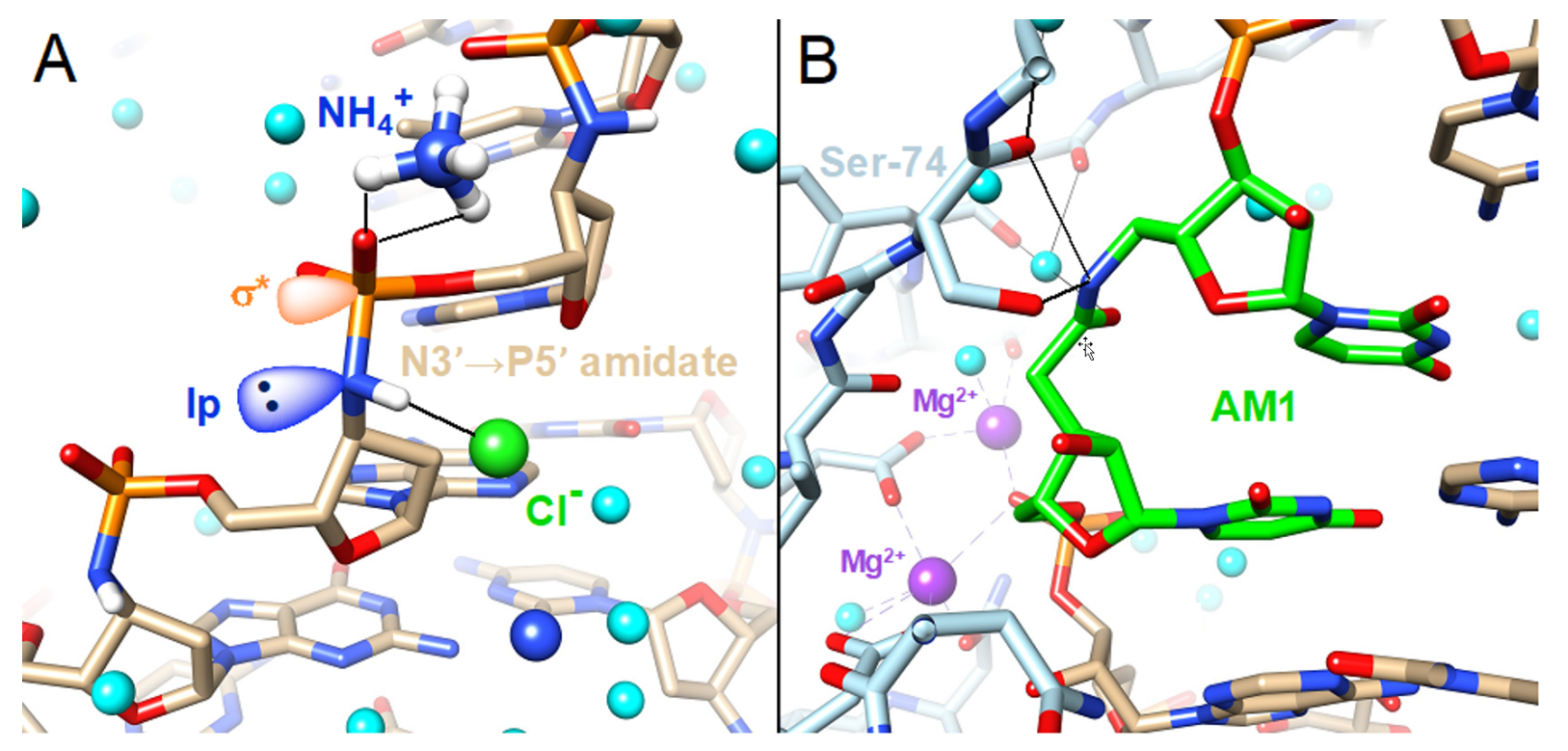

Figure 2: Crystal structures of (A) N3' $\rightarrow$ P5' phosphoramidate DNA (PDB ID 363D) [71] and (B) amide (AM1) RNA in complex with Bacillus halodurans RNase H (PDB ID 5VAJ) [73]. The relative orientation of the N3' $n$ and P-O5' $\sigma^{*}$ orbitals in the backbone of 3'-NP DNA are consistent with an anomeric effect. The 3 '-nitrogen is $\mathrm{H}$-bonded to a chloride anion (green sphere) and the phosphate group forms a salt bridge to ammonium. Water molecules are cyan spheres and $\mathrm{H}$-bonds are drawn with thin lines. 
little effect on the global structure [79]. Furthermore, siRNA duplexes with amide modifications at the 3 '-overhang region show enhanced endonuclease and 3'-exonuclease resistance [80]. Thus far, the AM1 modification has not found great success in antisense therapeutics, owing to RNAse $\mathrm{H}$ not recognizing a uniformly modified AM1-DNA:RNA heteroduplex. Recently, however, an 18-mer AM1-DNA gapmer was synthesized, with 4 AM1 linkages on each flank of the oligonucleotide [81]. Once bound to its RNA target, RNAse $\mathrm{H}$ was able to completely degrade the RNA in just 30 minutes, demonstrating the effectiveness of AM1 modifications in chimeric oligonucleotides for antisense therapeutics.

While this lack of charge was also believed to render AM1RNA incompatible with siRNA therapeutic strategies, as there was crystallographic data [82] that showed the main interaction between the phosphates of the RNA duplex and the Ago2 protein is electrostatic in nature, this was, however, not the case, owing to the observed increase in silencing activity for AM1modified siRNAs with amide linkages at specific sites [75] Structural insight into this observation was obtained using the crystal structure of the complex between Bacillus halodurans RNase $\mathrm{H}$ and the r(GAC ACC UGA UAM1UC) - d(GAA TCA GGT GTC) hybrid duplex [73]. Compared to the native complex, conformational changes in the RNA and protein were only observed around the site of the AM1 modification. Not only was the amide an ideal structural mimic of phosphate, it also possessed stabilizing hydrogen bonds between the amide $\mathrm{N}-\mathrm{H}$ and the main chain oxygen and side chain $\mathrm{O} \gamma$ of $\mathrm{S} 74$
(Figure 2B), explaining their tolerance towards efficient recognition by Ago2. Interestingly, however, disfavoring stabilizing interactions with Ago2 through an amide backbone modification can be therapeutically beneficial when placed in the proper site. This was exemplified by a recent study that placed a single AM1 backbone modification between nucleotides 1 and 2 at the 5 '-end of the siRNA passenger strand, whereby the off-target effects of that strand were abolished and the activity of the guide strand was restored [83].

\section{Phosphorodithioate}

The synthesis of phosphorodithioate (PS2)-modified oligonucleotides was first described in 1991 by the Caruthers group [84]. Typically, each 2'-deoxynucleoside 3'-phosphorothioamidite is prepared by phosphitylating the protected nucleosides with tris(pyrrolidino)phosphine under tetrazole catalysis, followed by immediate treatment with monobenzoylethanedithiol. The 3'-phosphorothioamidites are incorporated into an oligonucleotide by standard solid-phase synthesis conditions, however, the oxidation step is replaced with sulfurization by elemental sulfur (Scheme 2) [85]. It should be noted that more efficient sulfurization agents exist with faster kinetics and higher solubility in organic solvents, useful for automated synthesis, such as the Beaucage reagent [86]. Conveniently, during deprotection of the support-bound oligonucleotide, aminolysis removes the $\beta$-thiobenzoylethyl group from the backbone to generate the free PS2-modified oligonucleotide. This modification is achiral at the phosphorus atom (Figure 1C), and thus, unlike the phosphoromonothioate (PS) analogues (extensively

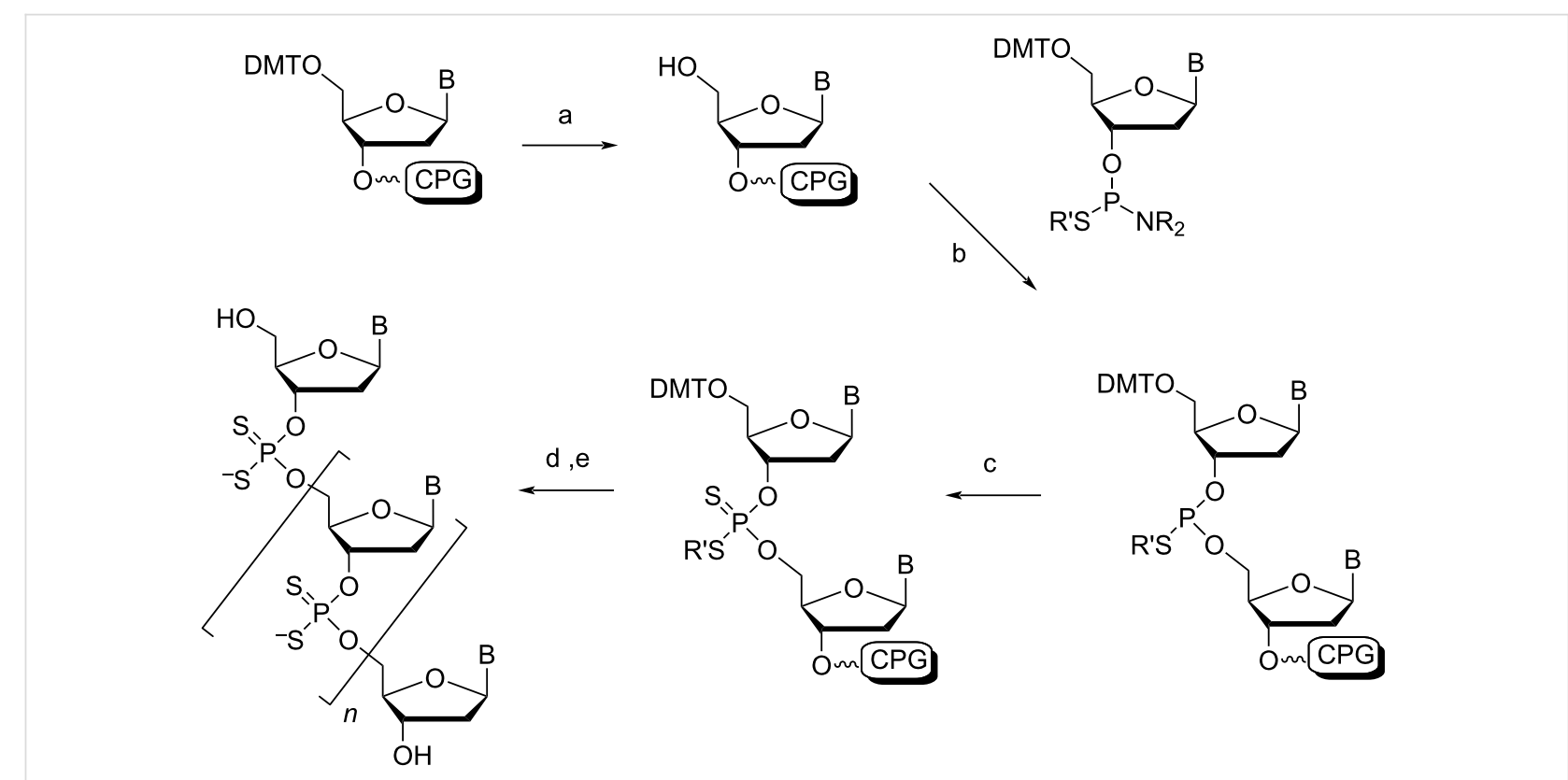

Scheme 2: Synthesis of a phosphorodithioate linkage by solid-phase synthesis. (a) detritylation; (b) tetrazole; (c) sulfurization, capping, then washing; (d) repeat steps a-c; (e) detritylate then deprotect with $\mathrm{NH}_{4} \mathrm{OH}$. $\mathrm{R}=$ pyrrolidino, $\mathrm{R}^{\prime}=\beta$-thiobenzoylethyl. Adapted from [85]. 
covered in other reviews $[18,42,87,88])$, the synthesized oligonucleotide is stereochemically pure. This simplifies their purification, as there is no longer the need to separate biochemically distinct diastereomers in order to make meaningful conclusions about the modification in a therapeutic or crystallographic context (although individual PS diastereoisomeric linkages can be resolved in electron density maps at sufficiently high resolution $[18,89])$. This modification has been attractive in antisense therapeutics as these altered oligonucleotides can form a hybrid duplex with unmodified RNA, which is recognized by RNase $\mathrm{H}$ $[89,90]$.

While the thermal stability of PS2-modified RNA duplexes slightly decreases compared to the unmodified duplex, there is an increase in nuclease stability, even relative to PS-modified duplexes [91]. Crystal structures of PS2-modified RNA duplexes were determined to be isomorphous to their native RNA counterpart, causing no perturbation in the ribose sugar conformation, nor the torsion angles of the backbone [92]. More interestingly, siRNA duplexes with PS2-modified sense strands showed an increase in binding affinity towards the Ago2 protein of the RISC complex $[92,93]$. The model based on the crystal structure of human Ago2 bound to an siRNA duplex demonstrated that PS2 moieties near the 3'-terminus of the sense strand lie in the vicinity of a hydrophobic patch that is surrounded by lysine and arginine residues [15]. The latter generate an electric field that could polarize sulfur atoms (the PS2 group still carries a negative charge), thereby enhancing the interaction of the PS2 moiety with the edge of phenylalanine as seen in the complex between PS2-modified anti-thrombin aptamer and thrombin [94] (Figure 3).

Commonly, internucleotide-modified oligonucleotides are coupled with 2'-substitutions in order to enhance or regain desirable therapeutic properties. For example, not only did introducing a 2'-OMe modification at the PS2 nucleotide sites of an siRNA duplex sense strand increase the thermal stability of the duplex to levels comparable to the unmodified variant, it also further improved the binding affinity to the Ago2 protein, hypothesized to be in part caused by a superior hydrophobic effect [92].

\section{Glycol nucleic acid}

Glycol nucleic acid (GNA) with its chiral, acyclic three-carbon backbone linked by phosphate is the simplest phosphodiesterbased nucleic acid analogue (Figure 1D). It contains one stereocenter allowing for the synthesis of either $(S)$-GNA or $(R)$-GNA where chirality is fixed by use of either $(R)$ or $(S)$ starting material, respectively. These simple nucleic acid building blocks were first synthesized in 1971 by Ueda et al. [96]. The group was able to synthesize adenine, cytosine, and uracil GNA ana-

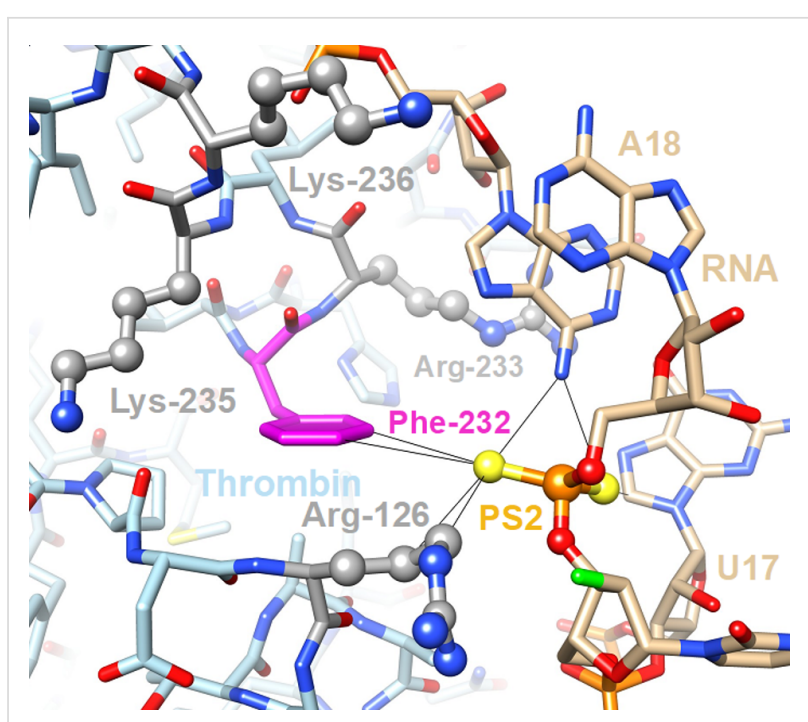

Figure 3: Close-up view of a key interaction between the PS2-modified antithrombin RNA aptamer and thrombin in the crystal structure of the complex (PDB ID 5DO4) [95]. An RNA-induced fit brings the PS2 moiety in close contact with the edge of Phe-232 (magenta carbon atoms) that forms a hydrophobic patch surrounded by four basic residues (side chains highlighted in ball-and-stick mode with carbon atoms colored in gray). These arginine and lysine residues generate an electric field that polarizes the thiophosphate moiety, thereby contributing to the 1000 -fold tighter binding of the PS2-modified RNA to thrombin relative to the parent aptamer.

logues by reacting these bases with glycerol $\alpha$-chlorohydrin or glycidol. The following year, the Seita group showed that thymine and guanine analogues could be prepared in a similar fashion [97]. Interestingly, both groups found that condensation of purine bases to yield GNA derivatives gave two dihydroxypropylated isomers: the N3 (I) and the N9 (II) dihydroxypropylated isomers. Using glycerol $\alpha$-chlorohydrin, the ratio of I/II was 1:4 with II being the preferred isomer but when using glycidol, this ratio shifted to $3: 1$ in the favor of the desired isomer $[96,97]$. From there on, the use of glycidol for the preparation of GNA analogues became the gold standard. The first GNA polymers were obtained through condensation with $N, N$ dicyclohexylcarbodiimide (DCC) giving rise to homopolymeric tetramers of either G-GNA or T-GNA [97]. In 1996, Acevedo and Andrews were the first to demonstrate the synthesis of GNA nucleoside phosphoramidite derivatives as well as the ability of the phosphoramidite derivatives to withstand solidphase conditions, inevitably laying the groundwork for GNA solid-phase synthesis [98]. Using the glycidol approach, Zhang et al. synthesized 18-mer oligonucleotides containing GNA-T monomers [99]. Starting from $(R)$-glycidol, the free hydroxy group is tritylated. The resulting product is then reacted with unprotected thymine which, in the presence of stoichiometric amounts of sodium hydride, results in the epoxide ring opening and the formation of the glycol backbone. The preamidite is then phosphitylated yielding the desired GNA-T 
amidite (Scheme 3). Recently, this simple acyclic nucleic acid backbone is of interest as a prospective evolutionary precursor of RNA [100]. Furthermore, GNA analogues with N2' $\rightarrow$ P3' phosphoramidate linkages have been studied as a potential alternative genetic system and they have been incorporated into siRNA duplexes to increase in vivo potency $[54,100]$

DNA oligomers containing GNA residues have been shown to form duplexes with DNA and RNA and to display self-pairing, whereby duplex formation was accompanied by hypochromicity $[97,99]$. In terms of stability, a single substitution from DNA to either (S)-GNA or $(R)$-GNA results in a decrease in $T_{\mathrm{m}}$ of $13{ }^{\circ} \mathrm{C}$ and $7{ }^{\circ} \mathrm{C}$, respectively. As the number of substitutions is increased, the $T_{\mathrm{m}}$ decreases in a non-linear fashion. Replacement of all residues of a DNA strand by either $(S)$-GNA or $(R)$-GNA results in the complete loss of duplex formation, thereby confirming the detrimental effect of single and/or multiple GNA incorporations on duplex stability [101,102]. However, Zhang et al. demonstrated that an all- $(S)$-GNA can form a duplex with RNA [99]. It has been shown that a GNA/GNA duplex exceeds the thermal stability of DNA/DNA and RNA/RNA duplexes of the same sequence (increase in $T_{\mathrm{m}}$ of $18-25^{\circ} \mathrm{C}$ ) $[99,101]$ Moreover, $(S)$-GNA and $(R)$-GNA do not cross-pair either in a parallel or antiparallel fashion; thus GNA:GNA duplex formation is limited to homochiral pairing between either $(S)$-GNA or $(R)$-GNA strands [103]. With respect to nuclease stability, Nielson et al. showed that a 17 mer oligonucleotide containing one T-GNA substitution has a nuclease half-life of 18-22 minutes in snake venom phosphodiesterase (SVPDE), thus exhibiting significantly higher stability compared to the parent strand [104]. Furthermore, Schlegel et al. showed that the position of the GNA substitution in a DNA/DNA duplex greatly influences its ability to resist 3 '-exonucleases. Their work showed that a single or double $(S)$ - or $(R)$-GNA substitution at the 3 ' end of a $\mathrm{dT}_{20}$ oligomer with a natural phosphodiester backbone greatly increases the oligonucleotide's ability to resist SVPDE. Furthermore, when moving the single or dinucleotide substitution to the penultimate position, a marked decrease in nuclease stability was observed. However, when these modifications where moved to the terminal positions, an 8- or 5-fold increase in nuclease resistance was observed for the $(S)$ - or $(R)$ isomer, respectively [54].
It is generally assumed that nucleic acid analogues require cyclic units in the backbone to generate the necessary conformational preorganization for duplex formation. This assumption does not hold true for GNA backbones where the destabilization caused by the shorter glycol moiety in DNA duplexes most likely stems from the structural incompatibility with the B-form deoxyribonucleotide-phosphate backbone. On the other hand, GNA-GNA duplexes form highly stable antiparallel duplexes that follow Watson-Crick base pairing rules [99]. GNA strands self-assemble into homochiral antiparallel righthanded $((S)$-GNA) and left-handed $((R)$-GNA) duplexes held together by Watson-Crick base pairs. Furthermore, these duplexes exhibit cross-strand base stacking consistent with A-form DNA and RNA duplexes [55].

Crystallographic studies have shown that (S)-GNA can form M-type helices (with metallo-base pairs) similar to A-form helices (with brominated base pairs). The M-type structure with 16 base pairs per turn and a helical pitch of $60 \AA$ (ca. $3.8 \AA$ helical rise) deviates significantly from the canonical A-form (11 base pairs/turn and ca. $2.6 \AA$ rise) and B-form (10 base pairs/turn and ca. $3.4 \AA$ A rise) duplexes [54,55,105-107]. GNA duplexes possess only one large groove which corresponds to the canonical minor groove, the canonical major groove is a convex surface. Furthermore, the glycol backbone adopts two conformations alternating between gauche and anti conformations such that each base pair contains one nucleotide in the gauche conformation and one in the anti conformation. There is also a large backbone-base inclination $\left(46^{\circ}\right.$ to $\left.-53^{\circ}\right)$ which results in zipperlike interstrand and reduced intrastrand base stacking interactions [103]. The crystal structure of an RNA duplex containing $(R)$-GNA revealed that this modification disrupts both the phosphate backbone and hydrogen bonding of an adjacent base pair whereas $(S)$-GNA has a minimal influence on the structure of the duplex [54] (Figure 4). Moreover, incorporation of $(S)$-GNA residues in the seed region of the antisense strand of siRNA was observed to mitigate off target effects [54].

\section{Sugar and nucleobase modifications 2'-O-Alkyl modifications}

Historically, the 2'-OMe modification (Figure 5A) was the first of its class. The synthesis of each 2'-OMe ribonucleoside re-
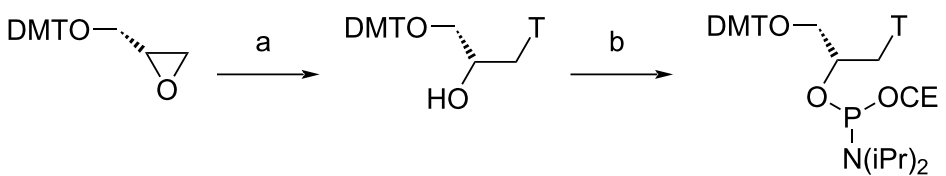

Scheme 3: Synthesis of the (S)-GNA thymine phosphoramidite from (S)-glycidyl 4,4'-dimethoxytrityl ether. (a) Thymine, NaH, DMF; (b) $\mathrm{CIP}\left(\mathrm{NiPr}_{2}\right)(\mathrm{OCE}),\left(\mathrm{iPr}_{2}\right)_{2} \mathrm{NEt}$. $\mathrm{T}=$ thymine. Adapted from [99]. 

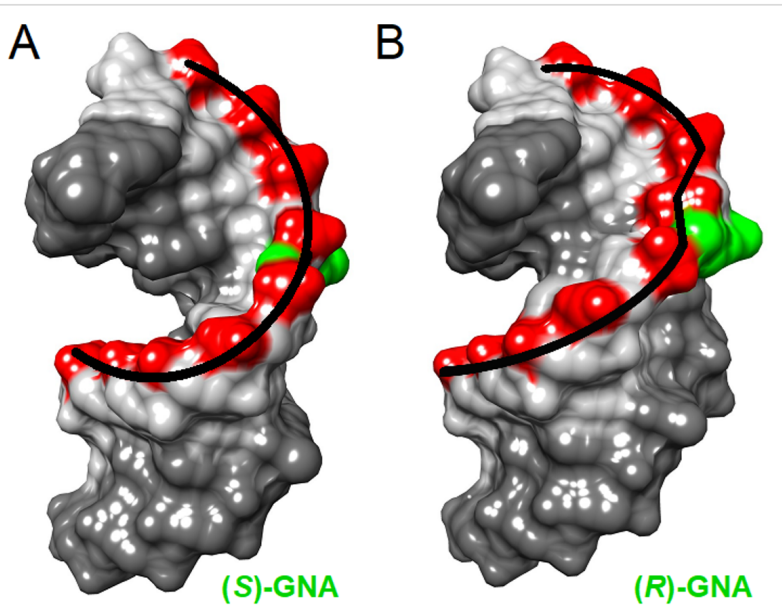

Figure 4: Surface models of the crystal structures of RNA dodecamers with single (A) (S)-GNA-T (PDB ID 5V1L) [54] and (B) $(R)$ GNA-T (PDB ID 5V1K) [54] nucleotides per strand. The presence of the $(R)$-GNA isomer introduces a kink in the backbone and causes local disruption of base stacking, in-line with a significantly reduced $T_{\mathrm{m}}$ relative to the $(S)$-GNA isomer.
(A)

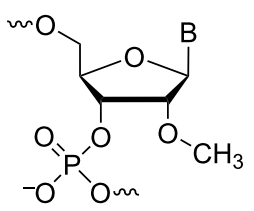

(B)

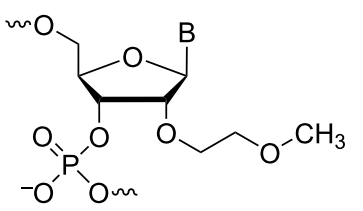

Figure 5: Structures of 2'-O-alkyl modifications. (A) 2'-O-methoxy RNA (2'-OMe RNA), (B) 2'-O-(2-methoxyethyl) RNA (2'-O-MOE RNA).

quired specific considerations [108]. Starting from 3',5'-O(tetraisopropyldisiloxane-1,3-diyl) (TIPDS) protected uridine, protection of $\mathrm{N} 3$ was needed in order to prevent methylation at this position (Scheme 4). The N3-benzoylated derivative could then be treated with methyl iodide in the presence of silver oxide in order to methylate the 2 - $-\mathrm{OH}$. A similar strategy was employed to synthesize 3',5'-O-TIPDS- $N^{4}$-benzoyl-2'- $O$ methylcytidine. Next, 3',5'-O-TIPDS- $N^{6}$-benzoyladenosine suffered from methylation at the nucleobase and thus, 6-chloro$9-\beta$-D-ribofuranosylpurine was instead used as the starting mate- rial. Once TIPDS protected, the 2'-OH could, once again, be selectively methylated with methyl iodide and silver oxide. The protected adenine base was regenerated by treatment with ammonia followed by benzoylation. Once the methyl group was incorporated into these ribonucleosides, the TIPDS group was selectively removed by tetrabutylammonium fluoride (TBAF) or hydrochloric acid treatment, followed by 5 '-tritylation. In the case of guanosine, this strategy for 2'-OH methylation was unsuccessful, owing again to undesired methylation at the nucleobase. Instead, the 5'-O-monomethoxytrityl derivative of $N^{2}$-isobutyrylguanosine was treated with diazomethane in dimethylformamide in the presence of tin chloride, affording both $2^{\prime}-O \mathrm{Me}$ and 3 '-OMe regioisomers. Fortunately, these isomers could be separated by silica gel column chromatography. Other synthetic approaches have since been developed [109-111], however, this pioneering work should be appreciated as nowadays, the 2 '-OMe phosphoramidites of each protected ribonucleoside are all commercially available.

The study of 2'-OMe modified oligonucleotides was stimulated by the fact that they bind to RNA with higher affinity than unmodified RNA or DNA, as well as their improved nuclease resistance [112], promoting their usefulness in antisense therapies. Unfortunately, it was determined that uniformly 2'-OMe modified RNA:RNA duplexes were not substrates for RNAse $\mathrm{H}$ [113]. Structural insights of this modification were determined from the crystal structure of a duplex of self-complementary 10-mer DNA strands with a single internal 2'-OMe modified adenosine [114]. This duplex adopted an overall A-form, with the sugars in the C3'-endo orientation and the two, well solvated methoxy groups, pointing into the relatively wide minor groove of the duplex.

It was shown that as the number of carbons in the $2^{\prime}-O$-alkyl chain increased, so too did the destabilizing effect towards RNA binding affinity [115]. Thus, it was initially believed that even though nuclease resistance increased with chain length, this destabilizing effect would render 2'-O-alkyl-modified RNA a less potent therapeutic agent. In 1994, there was crystallo-

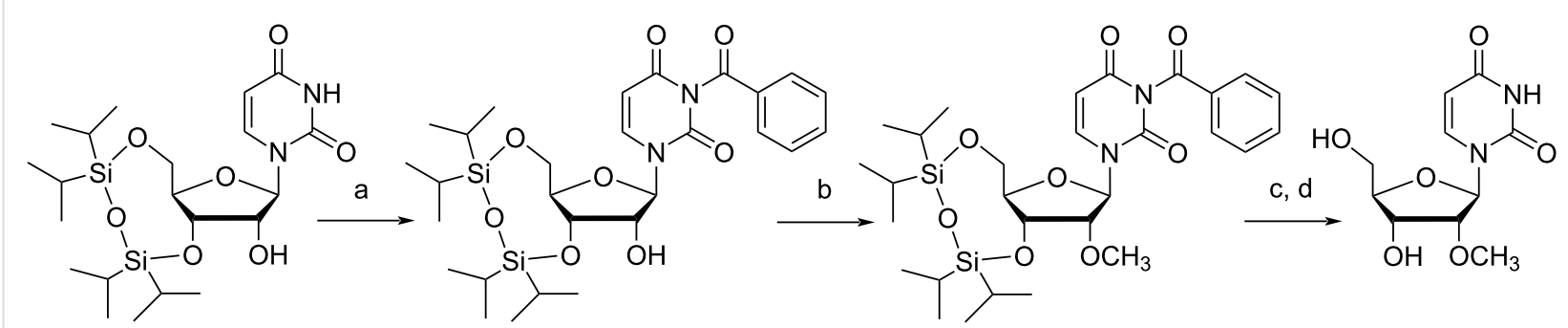

Scheme 4: Synthesis of the 2'-OMe uridine from 3',5'-O-(tetraisopropyldisiloxane-1,3-diyl)uridine. (a) Benzoyl chloride, triethylamine; (b) $\mathrm{CH}_{3} \mathrm{I}, \mathrm{Ag}_{2} \mathrm{O}$; (c) dilute $\mathrm{NH}_{4} \mathrm{OH}$; (d) $0.5 \mathrm{~N} \mathrm{HCl}$. Adapted from [108]. 
graphic evidence, however, that suggested the addition of a polarizable group in the longer 2'-O-alkyl chains that could hydrogen bond with nucleobases in the minor groove of the duplex would be well tolerated [114]. This supported the hypothesis that the 2'-O-[2-(methoxy)ethyl] (MOE) modification (Figure 5B) wouldn't lead to significant destabilization of the duplex, prompting its development.

The synthesis of 2'-O-MOE-modified ribonucleosides was first described in 1995 [116]. Since then, two practical strategies have been developed for synthesizing 2'-O-MOE ribonucleosides. For pyrimidines, this involves treating 2,2'-anhydrouridine with aluminum 2-methoxyethoxide, which attacks and inserts at the 2'-position, opening the ring and producing the nucleoside with the correct stereochemistry (Scheme 5) [117] Conveniently, this $2^{\prime}-O-M O E$ uridine can be converted to the cytidine derivative by 4-nitrophenylation, 3',5'-trimethylsilylation and finally, treatment with aqueous ammonia. In contrast, the purine synthetic route first uses the bis-silylating agent [methylene bis(diisopropylsilyl)chloride] (MDPS) to protect both the 5' and 3'-hydroxy groups [118]. The protected nucleoside can then be treated with 2-methoxyethyl bromide in the presence of NaHMDS in order to selectively alkylate the 2'-OH, followed by TBAF treatment to remove the MDPS protecting group.

The 2'-O-MOE soon became the gold standard alkyl modification, owing to its improvement in therapeutically relevant properties. Compared to $2^{\prime}-O M e$ RNA, the $2^{\prime}-O-M O E$ RNA analogue has similar or even increased RNA binding affinity, as well as a tenfold increase in nuclease resistance [119]. Moreover, compared the PS-DNA, 2'-O-MOE RNA has an increased thermal stability of $2{ }^{\circ} \mathrm{C}$ per modification, with similar nuclease resistance $[11,41]$. Rationale for the improved properties of the 2'-O-MOE modification was gained through the analysis of the crystal structure of a uniformly modified self-complementary 12-mer RNA duplex [58]. The duplex was observed to be in the A-form, with the sugar residues being in a C3'-endo conformation. The MOE substituents were in the gauche orientation, being well accommodated in the minor groove and making a stabilizing interaction with a trapped water molecule and the adjacent phosphate (Figure 6). It's this pre-organization of the MOE groups, making the duplex more rigid, which is hypothesized to cause the increase in RNA binding affinity. Furthermore, the increase in nuclease resistance is believed to be due to steric constraints from the MOE substituent and water molecule protecting the adjacent phosphate.
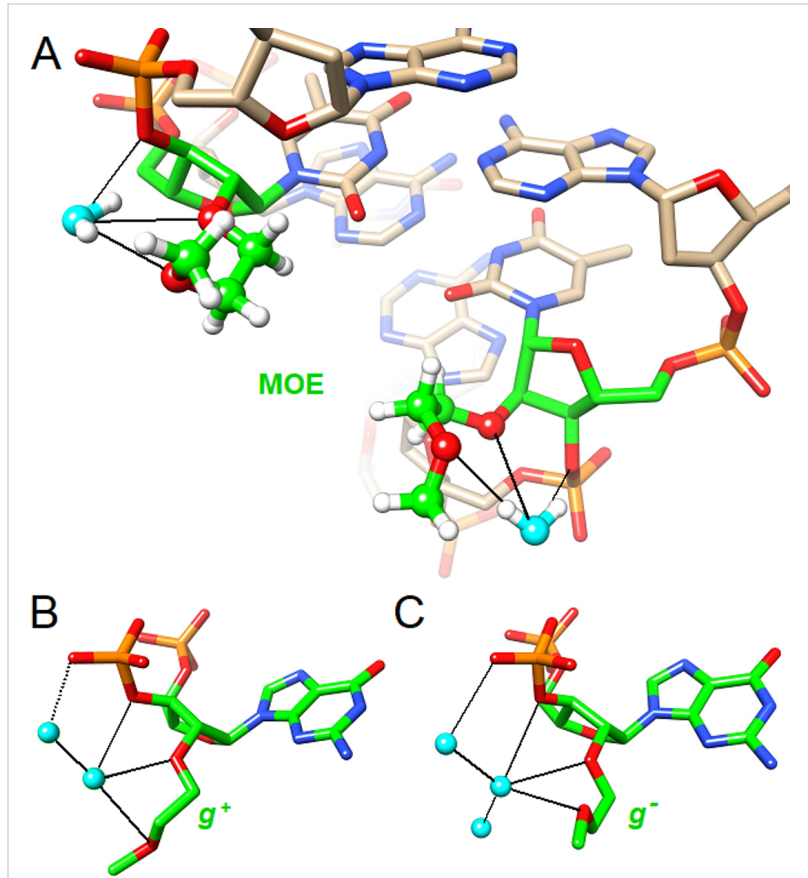

Figure 6: Structure of 2'-O-(2-methoxyethyl)-RNA (MOE-RNA). (A) View into the minor groove of an A-form DNA decamer with single MOE-T nucleotides per strand (PDB ID 411D, highlighted with green carbon atoms) [120]. Water molecules are trapped in a chelate-like manner between the O3', O2' and OC' (outer oxygen of the MOE substituent). (B) and (C) individual nucleotides from a crystal structure of an MOE-RNA dodecamer duplex (PDB ID 469D) [58]. Of the $24 \mathrm{MOE}$ substituents, 22 adopt a gauche conformation, either $g+$ or $g-$, whereby both trap a water molecule that can be linked to the 3'-phosphate via a water bridge.

Many other 2'-O-alkyl modifications have been synthesized and studied extensively, and are summarized elsewhere [41,121]. Importantly, while 2'-O-alkyl-modified RNA cannot activate

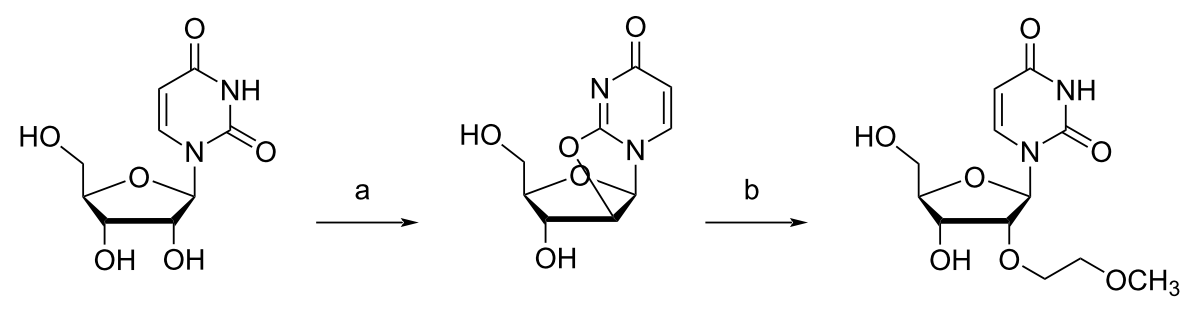

Scheme 5: Synthesis of the 2'-O-MOE uridine from uridine. (a) $(\mathrm{PhO})_{2} \mathrm{CO}, \mathrm{NaHCO}_{3}, \mathrm{DMA}, 100{ }^{\circ} \mathrm{C}$; (b) $\mathrm{Al}\left(\mathrm{OCH}_{2} \mathrm{CH}_{2} \mathrm{OCH}_{3}\right)_{3}$, reflux. Adapted from [117]. 
the RNAse $\mathrm{H}$ dependent degradation pathway, they can, however, act through a different therapeutic mechanism as steric blockers, inhibiting mRNA translation, RNA reverse transcription or RNA splicing [122-125].

\section{Locked nucleic acids (LNA)/bridged nucleic acids (BNA)}

Locked nucleic acids are a class of modified nucleosides which traditionally involve the incorporation of a methylene bridge between $\mathrm{C}^{\prime}$ ' and O2' of the ribose sugar (Figure 7A). This incorporation, as first reported by both Wengel and Obika, locks the nucleoside in the C3'-endo (north) conformation which allows for enhanced binding affinities towards both DNA and RNA targets [126,127]. Both ${ }^{1} \mathrm{H}$ NMR [127-129] and crystallographic studies [126] have been used to demonstrate the Northern puckering of the sugar and the anti orientation of the nucleobase. The key synthetic step in the synthesis of LNA involves the tosylation of a 4'- $C$-hydroxymethyl derivative, followed by a base-induced ring closure to afford the $2^{\prime}-O, 4^{\prime}-C$ linked bicyclic nucleoside derivative (Scheme 6) [127,128]. Incorporation of LNA into a variety of oligonucleotides with varying lengths and sequences has shown increased thermal stability when binding to either DNA or RNA complements with $T_{\mathrm{m}}$ increases of +1 to +8 and +2 to $+10{ }^{\circ} \mathrm{C}$, respectively [127,128,130-134]. The higher stabilization of RNA can be attributed to the preorganization of LNA nucleosides towards formation of A-form duplexes [128], whereas in DNA duplexes
LNA residues steer the conformation of the neighboring DNA monomers into the C3'-endo conformation [135,136]. These modifications have also been shown to confer a higher level of nuclease resistance than isosequential DNA or phosphorothioate modifications [137-141]. In combination with the high selectivity for RNA sequences, this makes LNA-modified oligonucleotides well suited for use as antisense therapeutics. Recent publications have used LNA's high affinity for RNA sequences in gapmer-designed antisense oligonucleotides for successful targeting of a key gene involved in TGF $\beta$ inhibition [142]. The inclusion of LNA nucleosides within a larger singlestranded DNA oligonucleotide has also allowed for subtle gene modifications to be implemented while evading mismatch repair (MMR) [143]. Furthermore, Ju et al. recently reported the use of LNA-based suppressors for the inhibition of viral miRNA through carbon dot-mediated delivery [144]. A diastereomer of LNA, $\alpha$-L-LNA (Figure 7B), also induces a higher affinity for both DNA and RNA complements in addition to providing a high stability against nucleases $[145,146]$. Unlike LNA, this diastereomer is a mimic of DNA instead of RNA and promotes a C2'-endo puckering of the sugar [147]. As a result, it has been shown to be better (fivefold) than other modified LNA analogues at knocking down target genes in vitro [145]. Also, these isomers have recently been shown to be useful in stabilizing streptavidin-binding aptamers [148], and in the use of antisense oligonucleotides for splice modulation through the induction of Dmd exon-23 skipping in mice in vitro [149].
(A)<smiles>[B]C1OCC2(COC)COCC(CO2)O1</smiles>

(B)

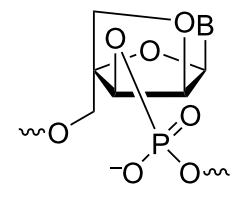

(C)<smiles>[B]C1OC2(COC)COP(=O)(OC)OC1N2</smiles>

(D)<smiles>[B]C1OC2CNP(=O)(OC)OC(COC)C1O2</smiles>

(E)

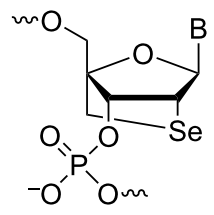

$(\mathrm{F})$<smiles></smiles>

(J)

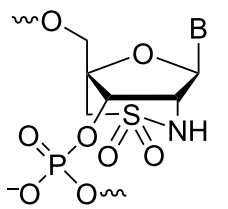

(G)<smiles>[B]C1OC2CCCC1(COC)OP(=O)(OC)OC2</smiles>

(K)

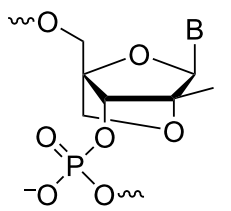

(H)<smiles>[B]C1OC2COC(COC)(CO2)C1(C)COP(=O)(OC)OC</smiles>

(I)

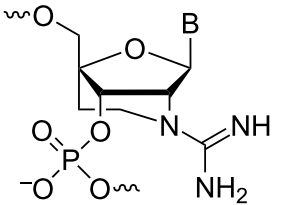

(L)<smiles>[B]C1OC2COC(COC)(CO2)C1(C)COP(=O)(OC)OC</smiles>

(M)

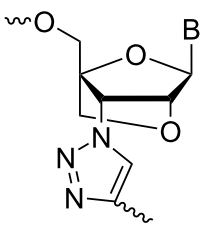

Figure 7: Structures of locked nucleic acids (LNA)/bridged nucleic acids (BNA) modifications. (A) LNA/BNA, (B) $\alpha$-L-LNA, (C) C2'-amino-LNA, (D) 3'-amino-2',4'-LNA, (E) seleno-LNA, (F) thio-LNA, (G) carba-LNA, (H) S-constrained ethyl (cEt) nucleic acid, (I) 2'-N-guanidino,4'-C-ethylene nucleic acid (GENA), (J) sulfonamide-bridged nucleic acid (suNA), (K) 2'-Me-LNA, (L) 6'-S-Me-2'-O,4'-C-ethylene-bridged nucleic acid (6'-S-Me-ENA), (M) triazole linked LNA. 


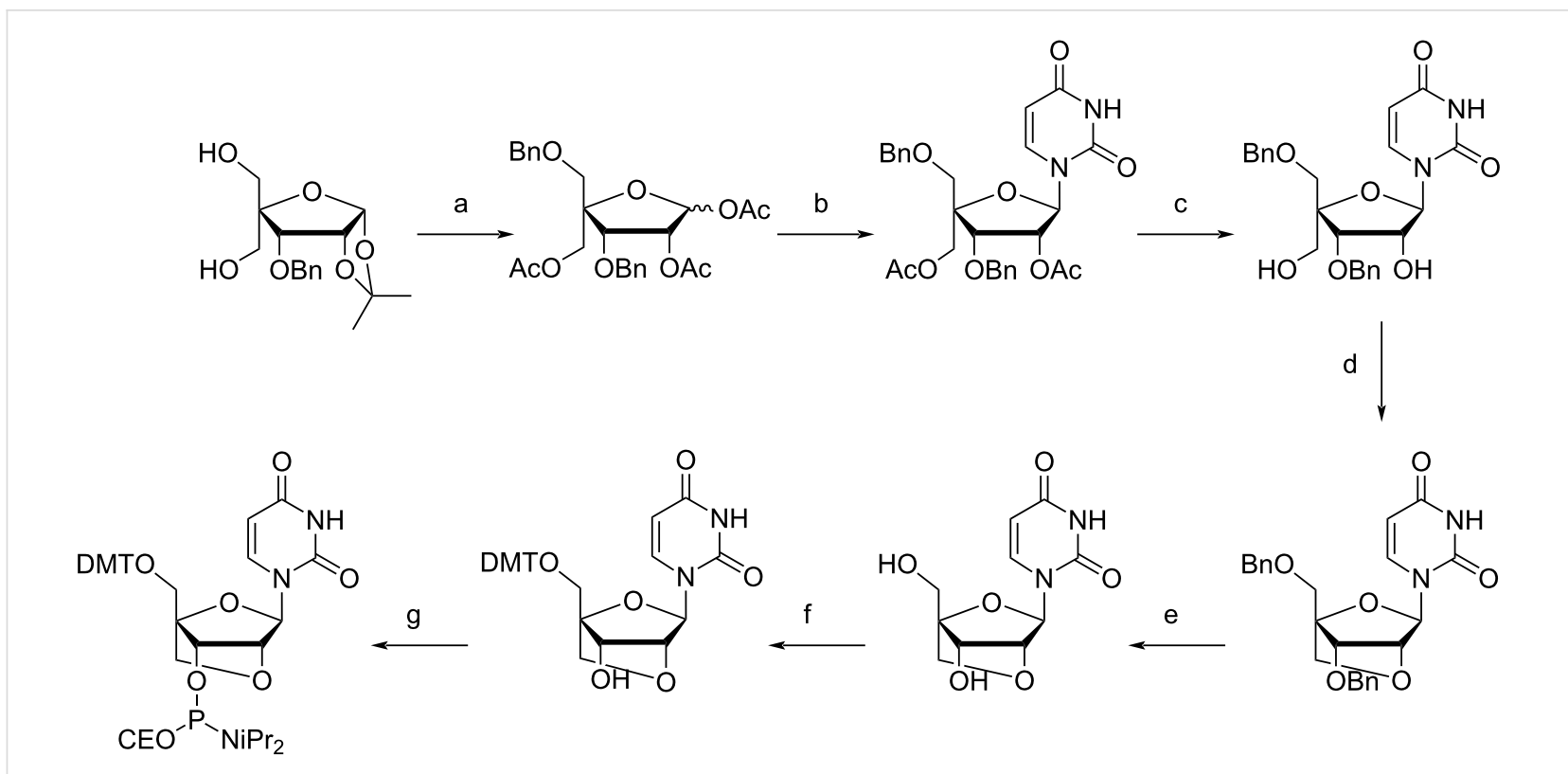

Scheme 6: Synthesis of the uridine LNA phosphoramidite. (a) i) $\mathrm{NaH}, \mathrm{BnBr}$, DMF, ii) acetic anhydride, pyridine, iii) $80 \%$ AcOH, iv) acetic anhydride, pyridine; (b) uracil, $\mathrm{N}, \mathrm{O}$-bis(trimethylsilyl)acetamide, TMS-triflate, acetonitrile; (c) $\mathrm{NaOCH}_{3}$, methanol; (d) i) p-toluenesulphonyl chloride, pyridine, ii) $\mathrm{NaH}$, DMF; (e) $\mathrm{H}_{2}, \mathrm{Pd}(\mathrm{OH})_{2} / \mathrm{C}$, ethanol; (f) DMTCl, pyridine; (g) $\mathrm{CIP}\left(\mathrm{NiPr}_{2}\right)(\mathrm{OCE})$, $\left(\mathrm{iPr}_{2}\right)_{2} \mathrm{NEt}$, dichloromethane. Bn = benzyl, Ac = acetyl. Adapted from [128].

Recently, a lot of attention has been paid to modifying the LNA scaffold to incorporate various heteroatoms, modify the bicyclic framework, and to change the location of the methylene bridge to tailor the properties of these nucleosides. The incorporation of nitrogen at $\mathrm{C}^{2}$ ' has been explored for further functionalization while retaining the LNA scaffold. Singh et al. were the first to report the synthesis of C2'-amino-LNAs (Figure 7C) in 1998 [150], with the synthetic route being optimized over time $[151,152]$. The stability of these derivatives is similar to those of LNA [150-152], with the added advantage of additional coupling reactions to fluorescent groups [151], or small molecules being possible either during solid-phase synthesis (SPS) $[153,154]$ or post synthetically $[155,156]$. Gapmer oligonucleotides that incorporate 2'-amino-LNA show increased uptake in organs such as the heart, liver, and lungs in comparison to other LNA modifications [145]. Nitrogen can also be incorporated at the C3' position in the form of a $3^{\prime}$-amino-2',4'-LNA (Figure 7D) monomer which has been shown to stabilize oligonucleotides similarly to unmodified LNA with a nuclease resistance greater than PS-modified oligonucleotides [157]. Incorporation of selenium at $\mathrm{C} 2$ ' in a thymine-bearing LNA nucleoside (Figure 7E) has been demonstrated to have a hybridization ability and a nuclease resistance that are highly reversible in response to redox changes of the selenium atom [158]. Recent work has also looked at this modification in LNA nucleosides bearing an adenine base [159], but this nucleoside was found to be highly sensitive to heat, making its incorporation into oligonucleotides challenging. Thio-LNA (Figure 7F), which has sulfur incorporated at the $\mathrm{C} 2$ ' position, has similar binding properties as amino-LNA and $\beta$-D-LNA, but with varying biodistribution patterns and a higher cellular uptake in mice [145]. Work looking at carba-LNA, which lacks the $\mathrm{O} 2$ ' functionality, has shown the importance of the oxygen atoms in hybridizing to complementary RNA [160]. Unsubstituted carba-LNA (Figure 7G), which lacks a hydrophilic substituent at C2', leads to a decrease in heteroduplex stability [160]. This agrees with the observation in the crystal structure of an LNA-modified DNA duplex where the 2'-oxygen acts as an H-bond acceptor for water, potentially making a favorable contribution to the increased pairing affinity of LNA [161].

Constrained ethyl (cEt) nucleic acids (Figure 7H), which contain a [2.2.1] tricyclic core, have been developed and show improved potency when compared to second generation 2'- $O$ MOE antisense oligonucleotides [162,163]. The cEt also demonstrate an improved toxicity profile in comparison to standard LNA ASOs [162]. The arduous synthesis of the nucleoside analogues has been refined to minimize the number of needed stereochemical adjustments and overall steps [164]. ASOs containing these modified nucleosides have demonstrated promising antitumor activity for lymphoma and lung cancer [165].

Numerous other LNA analogues have been constructed including, but not limited to, 2 '- $N$-guanidino,4'- $C$-ethylene (GENA) (Figure 7I) [166], sulfonamide-bridged (suNA) (Figure 7J) 
[167], 2'-Me LNAs (Figure 7K) [168,169], 6'-Me-2'-O,4'-Cethylene-bridged (6'-Me-ENA) (Figure 7L) [170], and various triazole-linked LNA (Figure 7M) [171,172] that have all shown the ability to modulate LNA properties.

\section{Arabinose and fluoroarabinose nucleic acids}

Arabino nucleic acids (ANA) are analogs of RNA where the hydroxy group at $\mathrm{C}^{\prime}$ ' is inverted (Figure $1 \mathrm{G}$ ). In fluoroarabino nucleic acids (FANA) this C2' hydroxy group is replaced by fluorine. Arabino- and fluoroarabino nucleosides have demonstrated anticancer and antiviral activities (as reviewed in [173]). $\beta$-D-Arabinonucleosides of pyrimidines can be prepared from 2,2'-anydronucleosides [174] and purines from approaches which include condensation of the nucleobase with 2,3,5-tri- $O$ benzyl-D-arabinofuranosyl chloride [175]. The 2'-fluoro- $\beta$-Darabinofuranose nucleosides can be prepared by coupling of the nucleobase with 3,5-di- $O$-benzoyl-2-deoxy-2-fluoro- $\alpha$-D-arabinofuranosyl bromide (Scheme 7) [176-180]. Both $\beta$-D-arabino and 2 '-fluoro- $\beta$-D-arabinofuranose nucleosides can be converted to phosphoramidite derivatives for incorporation into oligonucleotides for solid-phase synthesis [178,181-184].

Hybridization studies of uniformly modified ANA of mixed nucleobase composition to complementary RNA revealed reduced thermal stability relative to the corresponding DNA/ RNA duplex by approximately $1.5{ }^{\circ} \mathrm{C}$ per modification $[182,183]$. A significant reduction in stability of the duplex was observed in the binding of ANA to complementary DNA relative to the DNA duplex [182,183]. In contrast, FANA of mixed nucleobase composition displayed improved binding with both complementary DNA and RNA, relative to DNA/DNA and DNA/RNA duplexes by approximately $1{ }^{\circ} \mathrm{C}$ and $0.5{ }^{\circ} \mathrm{C}$ per modification, respectively [178]. The 2 '-stereoisomer of FANA, FRNA also demonstrates improved binding to RNA, relative to DNA [185]. Circular dichroism spectra of FANA/RNA and ANA/RNA duplexes show similarity to that of DNA/RNA $[178,183]$. Both ANA and FANA demonstrate good stability to nucleases [183,186]. Hybrid duplexes of ANA and FANA with complementary RNA were substrates of RNase H, with greater cleavage of the RNA strand observed for the latter, demon- strating the gene silencing potential of these analogs [183,186]. Uniformly modified phosphorothioate (PS) FANA forms a duplex with RNA with a higher $T_{\mathrm{m}}$ relative to the PS-DNA/ RNA duplex, however, RNase H-mediated cleavage of RNA was diminished for the duplex formed with PS-FANA relative to PS-DNA [187]. Improved cleavage by RNase H was observed with chimeric PS-FANA/DNA [187]. PS-FANA/DNA chimera with either flanked or alternating segments of FANA residues, as demonstrated by knockdown of $c-M Y B$ mRNA with a persistent silencing effect [188].

A $1.55 \AA$ crystal structure of a Dickerson-Drew dodecamer containing fluoroarabinothymine revealed that these modified nucleotides adopt an $\mathrm{O}^{\prime}$-endo (east) conformation that is readily accommodated in a B-form duplex [189] (Figure 8A). Fluoroarabinothymine in an A-form DNA duplex had a northern conformation (Figure 8B,C) whereas arabinouridine in either an A- or B-form environment had a south-eastern conformation (Figure 8D,E), suggesting greater flexibility for FANA versus ANA [190]. NMR structures of hairpin duplexes consisting of RNA and either FANA or ANA stems suggested that both modifications adopt an O4'-endo sugar pucker [191,192]. The O4'-endo sugar conformation has been reported for the DNA strand in DNA/RNA hybrid duplexes, the natural substrate of RNase H $[193,194]$. Structures of duplexes containing FANA and FRNA (Figure 8F) have revealed that thermal stabilization may be attributed to nonconventional hydrogen bonds in the backbone [195-197]. Gene silencing by RNAi has also been explored with siRNA containing FANA residues [198]. These studies have shown that FANA is accommodated in the sense strand and 5'-end and 3'-termini of the antisense strand of the siRNA [198].

\section{C4'-Modified nucleic acids}

Modifications at the $\mathrm{C} 4$ ' sugar position (Figure $1 \mathrm{H}$ ) have long been desirable as a means of modulating the properties of nucleic acids without interfering with Watson-Crick pairing. Incorporations at $\mathrm{C} 4$ ' are close in proximity to both the $3^{\prime}$ and 5 '-neighboring phosphate groups, allowing for a tailoring of the nuclease resistance [200]. In 2011, Rosenberg demonstrated the

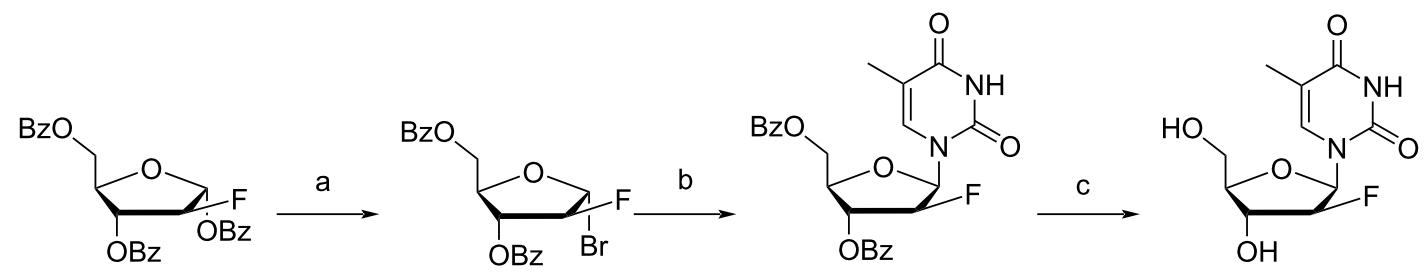

Scheme 7: Synthesis of the 2'-fluoroarabinothymidine. (a) $30 \% \mathrm{HBr}$ in acetic acid; (b) 2,4-bis-O-(trimethylsilyl)thymine, carbon tetrachloride; (c) $\mathrm{NH}_{4} \mathrm{OH}$, methanol. $\mathrm{Bz}$ = benzoyl. Adapted from [177]. 
A

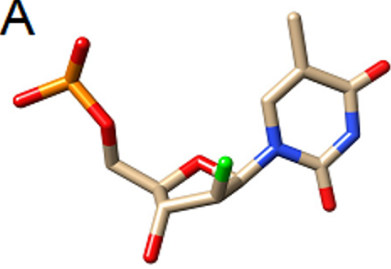

B-form FANA, O4'-endo

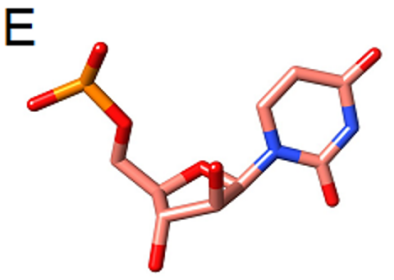

A-form ANA, C1'-exo

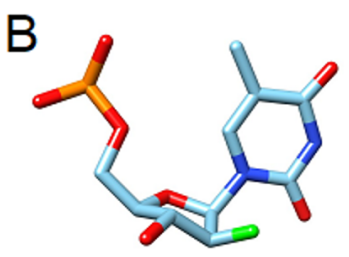

A-form FANA, C3'-endo

$\mathrm{F}$

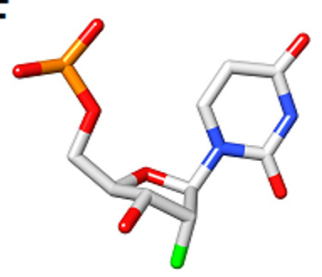

A-form FRNA, C3'-endo
C

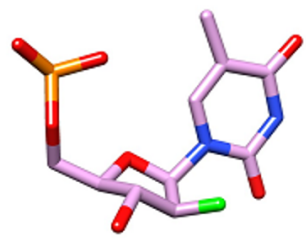

A-form FANA, C4'-exo

G

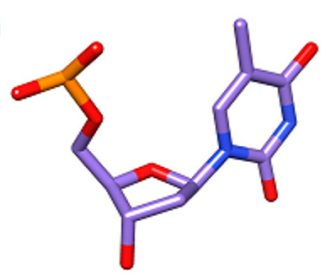

B-form DNA, C2'-endo

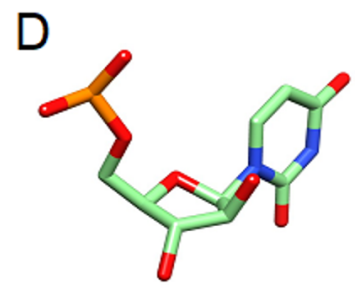

B-form ANA, C1'-exo

$\mathrm{H}$

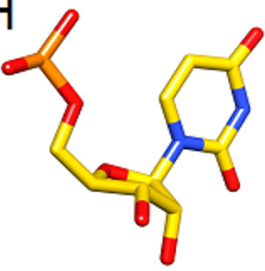

A-form RNA, C3'-endo

Figure 8: Sugar puckers of arabinose (ANA) and arabinofluoro (FANA) nucleic acids compared with the puckers of the fluoro-ribonucleic acid analog (FRNA) as well as DNA and RNA. (A) FANA-T in B-form DNA (PDB ID 388D) [189]. (B) FANA-T in A-form DNA (PDB ID 2FIL, duplex 1) [190].

(C) FANA-T in A-form DNA (PDB 2FIL, duplex 2) [190]. (D) ANA-U in B-form DNA (PDB ID 2FII) [190]. (E) ANA-U in A-form DNA (PDB ID 2FIJ) [190]. (F) FRNA-U in A-form RNA (PDB ID 3P4A) [62]. (G) B-form DNA (PDB ID 388D) [189]. (H) A-form RNA (PDB ID 5DEK) [199].

favorable binding properties of an oligothymidylate modified with 4'-methoxy or 4'-(2-methoxyethoxy) functionalities (Figure 9A,B) [201]. These modified nucleic acids were found to have superior hybridization behaviors towards both complementary DNA (see Figure $8 \mathrm{G}$ for pucker) and RNA (see Figure $8 \mathrm{H}$ for pucker) with sugar puckers in the northern (C3'-endo) and southern (C2'-endo) configurations for the respective alpha and beta isomers [201]. In 2015, this work was extended to incorporate these modifications into oligonucleotides containing all four bases [202]. $N$-Iodosuccinimide promoted the alkoxylation of the 4'-5'-enol acetates yielded the corresponding 5'-acetoxy-5'-iodo-4'-methoxy intermediates [202]. These intermediates were hydrolyzed with a mixture of triethylammonium bicarbonate (TEAB) and $N, N$-dimethylformamide (DMF) followed by a sodium borohydride reduction to give the 4'-alkoxy products [202]. The 4'-methoxy-2'-deoxynu-
(A)<smiles>[B]C1CC(OP(=O)(OC)OC)C(COC)(OC)C1</smiles>

(E)<smiles>[B]C1OC2(COC)OC1C(OP(=O)(OC)OC)C(OC)C2OC</smiles>

(F)

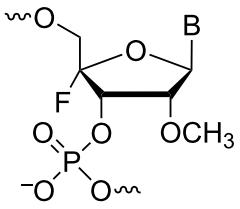

(B)<smiles>[B]C1CC2(OP(=O)([O-])OC)OC(COC)(CO1)C2OC</smiles>

G)<smiles>[B]C(F)(F)OC(OC)C(OC)(OC)OP(=O)(OC)OC</smiles>

(D)<smiles>[B]C(F)(F)OC(F)(COC)COP(=O)(OC)OC</smiles>

(H)<smiles>[B]C1OC(O)C(OP(=O)(OC)OC)C(F)C1O</smiles>

(I)<smiles>[B]C1OC2(CN)C(OC)CC(OP(=O)([O-])OC)C1C2OC</smiles>

(J)

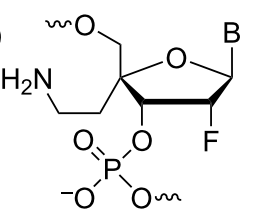<smiles>[B]C1OC2(COC)CC(O)C(OP(=O)(OC)O2)C1O</smiles>

Figure 9: Structures of C4'-modified nucleic acids. (A) 4'-methoxy, (B) 4'-(2-methoxyethoxy), (C) 2',4'-difluoro (2',4'-diF) RNA, (D) 2',4'-difluoro (2',4'diF) ANA, (E) 2',4'-dimethoxy RNA, (F) 2'-methoxy,4'-fluoro RNA, (G) 2'-fluoro,4'-methoxy ANA, (H) 4'-fluoro RNA, (I) 4'-C-aminoalkyl-2'-O-methyl, (J) 4'-C-aminoalkyl-2'-fluoro, (K) 4'-C-guanidinocarbohydrazidomethyl. 
cleosides exhibited high resistance towards depurination under acidic conditions [202]. In contrast, nucleosides that are modified with 4'-fluoro modifications have more labile glycosidic linkages under similar conditions [203,204]. Rosenberg attributed this contrast to the electronegativity differences between the groups and the effect this would have on the stabilization of the resulting oxocarbenium ion [202]. Oligomers modified with the 4'-methoxy modification hybridized better to complementary RNA, rather than DNA, due to the N-type conformation of the sugar pucker, as confirmed by NMR [202]. These same oligomers exhibited half-lives of approximately 40 minutes in the presence of phosphodiesterase I [202]. In contrast, the natural DNA sequence had a half-life of $1 \mathrm{~min}$ [202].

The incorporation of fluorine at the C4' position has long constituted a challenge owing to the instability of the glycosidic bond in the resulting nucleosides. This modification is desirable due to its involvement in the mode of action of the natural antibiotic nucleocidin $[203,205]$. Damha reasoned that the incorporation of fluorine at both $\mathrm{C} 2$ ' and $\mathrm{C} 4$ ' could lead to a stable nucleoside due to the glycosidic bond stabilization brought about by 2'-fluorination [206] which turned out to be correct after successful isolation of both 2',4'-diF-rU and 2',4'-diF-rC nucleosides (Figure 9C) [206]. Through NMR, these nucleosides were found to be essentially locked in the northern (C3'-endo) sugar pucker, albeit without the need for the bicyclic structures typical for locked nucleic acids [206]. The 2',4'-diF-rU nucleoside was introduced into an RNA by way of an $\mathrm{HCV}$ polymerase and extended to give a full-length oligonucleotide product, whereas 2',4'-diF-rUTP inhibited RNA synthesis at the early stages of dinucleotide-primed reactions [206]. Standard solid-phase synthesis allowed for the incorporation of this modified nucleoside into both RNA and DNA oligonucleotides. The impact on stability was found to be minimal in the case of RNA/RNA duplexes; mildly destabilizing with RNA/ DNA hybrid duplexes; and highly destabilizing when incorporated into the DNA strand of DNA/RNA or DNA/DNA duplexes [207]. Damha attributed this destabilization to structural distortions caused by A/B junctions within the helical structures [207].

2',4'-diF-modified siRNA sequences were capable of triggering RNAi with high efficiency, and the incorporation of multiple residues in the guide (antisense) strand yielded more potent siRNAs than those containing LNA or FANA modifications [207]. 2',4'-diF-ANA (Figure 9D) also adopted the northern (C3'-endo) sugar pucker despite the 2 '- $\beta \mathrm{F}$, which generally leads to the adoption of a southern or eastern pucker [208]. This monomer was found to have minimal effects on the thermal stability of nucleic acid duplexes. However, when incorporated into a DNA/RNA hybrid duplex it was shown to decrease the rate of both human and HIV reverse transcriptase-associated RNase H-mediated cleavage [208]. In 2018, the work was expanded to include 2',4'-diOMe-rU, 2'-OMe,4'-F-rU, and 2'-F,4'-OMe-araU nucleosides (Figure 9E,F,G) [209]. This work reinforced the notion that both 4 '-OMe and 4'-F modifications steer the sugar pucker towards a C3'-endo (north) conformation [209], even in the presence of C2' groups that would favor a different puckering of the ribose sugar. The 4'-modifications provided either a small stabilizing or destabilizing effect depending on the type of underlying duplex, and these 4'-substituents were able to modulate the binding affinities for the parent 2'-modifed oligonucleotides [209]. siRNA containing inserts of the C4' $\alpha$-epimer of 2'-F,4'-OMe-rU, in either the sense or antisense strands, triggered gene silencing with efficiencies comparable to that of 2'-F-rU [210].

Recently, Zhou provided the first synthesis of a 4'-F-rU (Figure 9H) phosphoramidite which was stable enough to then be incorporated into longer oligonucleotides through standard solid-phase synthesis (Scheme 8) [211]. They found that the modified 4'-F-rU ribonucleotide had a high resemblance to the unmodified uridine, allowing it to be used as a probe for RNA structure determination through ${ }^{19}$ F NMR [211]. This modification led to RNA which was stable and predominantly in the C3'-endo (north) conformation [211], similar to the 2',4'-diFRNA previously reported by Damha [208]. Zhou reasoned that because 3'-O- $\beta$-glucosylated nucleocidin, an intermediate in the biosynthetic pathway of nucleocidin, was stable, they may be able to successfully achieve the synthesis of the 4'-F-rU phosphoramidite through a selective protection of the hydroxy groups in stages [211]. Starting with a prepared 5'-iodo-4'-fluorouridine analogue that had been used in previous attempts of this synthesis, they removed the acetyl protecting groups at C3' and $\mathrm{C}^{2}$ ' with $\mathrm{NH}_{3} / \mathrm{MeOH}$ to give 5'-iodo-4'-fluorouridine [211]. Selective protection of the 2'-OH with TBDMS-Cl followed by protection of the 3'-OH with an acetyl group gave the fully protected intermediate [211]. Treatment of this intermediate with $\mathrm{m}$-CPBA in the presence of a phase-transfer catalyst in acidic medium gave the resulting 5'-OH compound [211]. The authors reported no transfer of the 2'-TBDMS group onto the 5'-OH, however, following removal of the 3'-O-acetyl group with $\mathrm{NH}_{3}$ / $\mathrm{MeOH}$, some TBDMS transfer to the C3' position is seen [211]. 5 -DMT protection then led to the pre-amidite [211]. ${ }^{19} \mathrm{~F}$ NMR results show that not only does this modification allow for discernment between ssRNA and dsRNA, but it also allows for the identification of mismatches and the binding of RNA-processing proteins with chemical shift dispersions as large as $4 \mathrm{ppm}$, suggesting that this modification has a wide use for the determination of a variety of RNA structures through NMR spectroscopy [211]. 


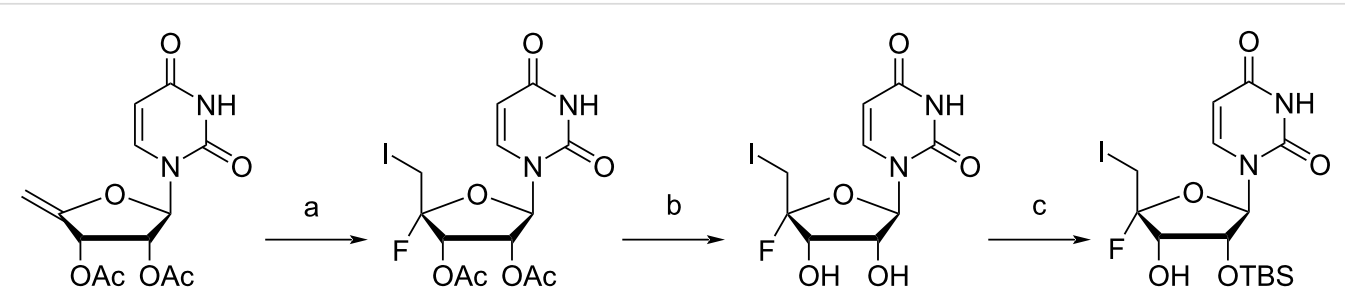

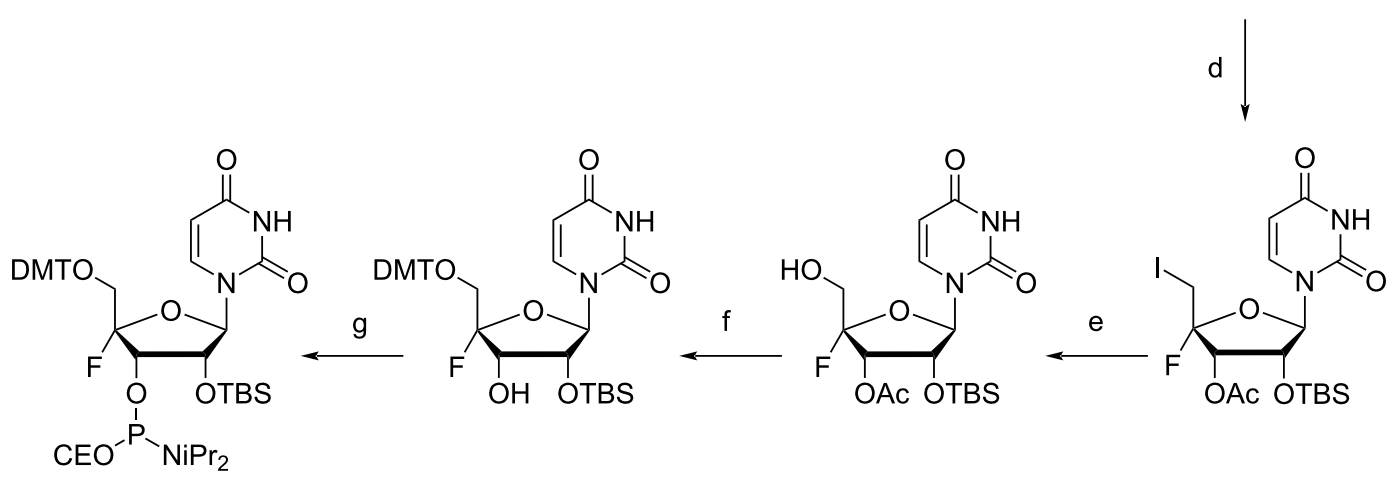

Scheme 8: Synthesis of the 4'-F-rU phosphoramidite. (a) AgF, $\mathrm{I}_{2}$, dichloromethane, tetrahydrofuran; (b) $\mathrm{NH}_{3}$, methanol; (c) $\mathrm{TBS}^{-\mathrm{Cl}}, \mathrm{AgNO}_{3}$, pyridine, tetrahydrofuran; (d) acetic anhydride, dimethylaminopyridine, pyridine; (e) tetrabutylammonium hydroxide, trifluoroacetic acid, $m$-chloroperoxybenzoic acid; (f) (i) $\mathrm{NH}_{3}$, methanol (ii) DMTCl, pyridine; (g) $\mathrm{CIP}\left(\mathrm{NiPr}_{2}\right)(\mathrm{OCE})$, 1-methylimidazole, ( $\left.\mathrm{PP}_{2}\right)_{2} \mathrm{NEt}$, dichloromethane. TBS = tert-butyldimethylsilyl. Adapted from [211].

In contrast, the incorporation of 4'- $C$-aminoalkyl-2'-O-methyl (Figure 9I) nucleosides leads to a slight destabilization of helical structures due to the adoption of a C2'-endo (south) conformation [212,213]. When fluorine is incorporated at C2' instead of 2'-OMe (Figure $9 \mathrm{~J}$ ), these 4'- $C$-aminoalkyl nucleosides are found to stabilize both dsRNA and siRNA to a larger extent [214]. The incorporation of 8 nucleosides into an siRNA passenger strand showed RNAi activity identical to the unmodified siRNA, with $50 \%$ of the siRNA strands remaining intact after $48 \mathrm{~h}$ in $20 \%$ BSA [214]. Recent work on the synthesis of novel 4'-C-guanidinocarbohydrazidomethyl-5-methyluridine (GMU) (Figure 9K) has shown that functionalizing the C4' position with guanidinium leads to siRNAs with increased thermal stability $\left(1-3{ }^{\circ} \mathrm{C} / \mathrm{mod}\right)$ and improved stability in human serum [215]. These guanidinium-modified siRNAs also lead to sustained gene silencing with only picomolar concentrations after $96 \mathrm{~h}$ of transfection [215]. Their qPCR experiments show that the cause of this sustained gene silencing activity is due to enhanced guide strand recruitment within the RISC complex [215].

\section{3'-Fluorohexitol nucleic acids (FHNA)}

Herdewijn was the first to describe the synthesis as well as the biophysical, structural, and biological characterization of hexitol nucleic acids (HNA), mannitol nucleic acids (MNA), and altritol nucleic acids (AtNA) [216-220]. These carbohydrate-modified nucleosides incorporate a six-membered pyranose ring in place of the furanose ring found in unmodified
DNA and RNA, with the nucleobase positioned at the C2' position in an axial orientation mimicking the C3'-endo (north) sugar puckering of furanose nucleosides [221]. MNA and AtNA possess an additional hydroxy group at the C3' position in the $R$ and $S$ configurations, respectively [219,220]. HNA was found to bind to complementary RNA in an antiparallel, sequence-dependent fashion, leading to the stabilization of HNA/RNA duplexes [218]. HNA also stabilizes HNA/DNA duplexes but to a smaller degree due to differences in minor groove solvation [222]. mRNA translation experiments have shown that HNA can function as a steric blocking agent of Ha-ras in cell-free experiments [223]. AtNA/RNA displays higher thermal stability when compared to HNA/RNA and natural nucleic acid controls [220]. In contrast, the introduction of MNA leads to duplex destabilization due to unfavorable steric clashes and limited nucleoside preorganization [219].

In 2011, a work detailing the first synthesis of both isomers of 3'-fluoro-modified hexitol nucleic acid (FHNA and Ara-FHNA) (Figure 1I) was published (Scheme 9 and Scheme 10) [221]. The incorporation of fluorine has long been used in siRNA [224], miRNA [225], and for ${ }^{19}$ F NMR structural studies of nucleic acids [211]. It was proposed that the incorporation of fluorine at the C3' position of HNA could further expand its use as a potential antisense therapeutic [221].

The published data show that incorporation of a 3 '-fluorine atom in the trans-diaxial orientation relative to the base in 


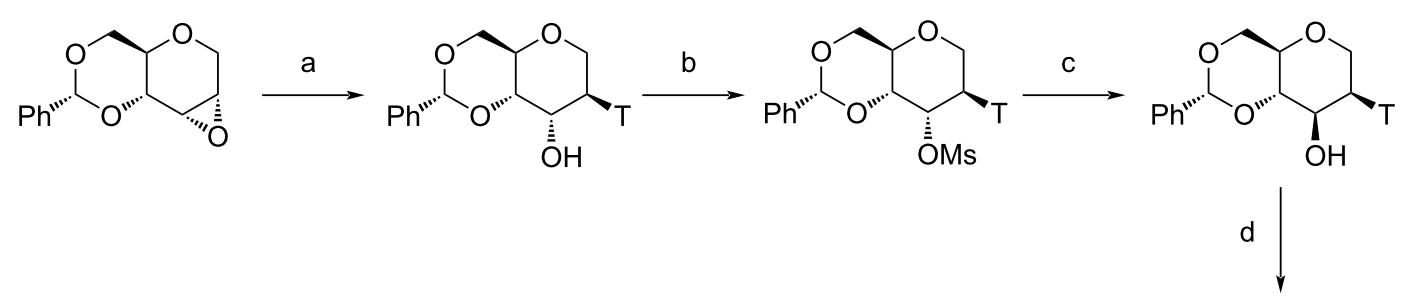

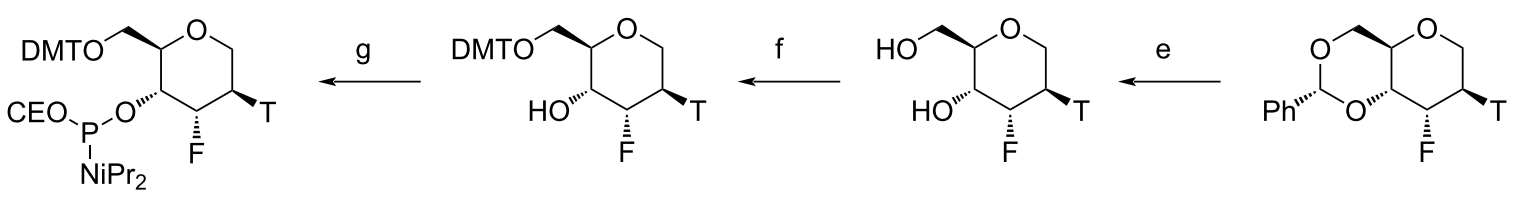

Scheme 9: Synthesis of the thymine FHNA phosphoramidite. (a) thymine, 1,8-diazabicyclo[5.4.0]undec-7-ene, acetonitrile; (b) methanesulfonyl chloride, pyridine; (c) aq $\mathrm{NaOH}, 1$,4-dioxane; (d) nonafluorobutanesulfonyl fluoride, 1,8-diazabicyclo[5.4.0]undec-7-ene, tetrahydrofuran; (e) $\mathrm{H}_{2}$, $\mathrm{Pd}(\mathrm{OH})_{2} / \mathrm{C}$, methanol; (f) DMTCl, pyridine; (g) $\mathrm{P}\left(\mathrm{NiPr}_{2}\right)_{2}(\mathrm{OCE}), 1 \mathrm{H}$-tetrazole, NMI, DMF. Ms = methanesulfonyl, $\mathrm{Ph}=\mathrm{phenyl}$, $\mathrm{T}=$ thymine. Adapted from [221].

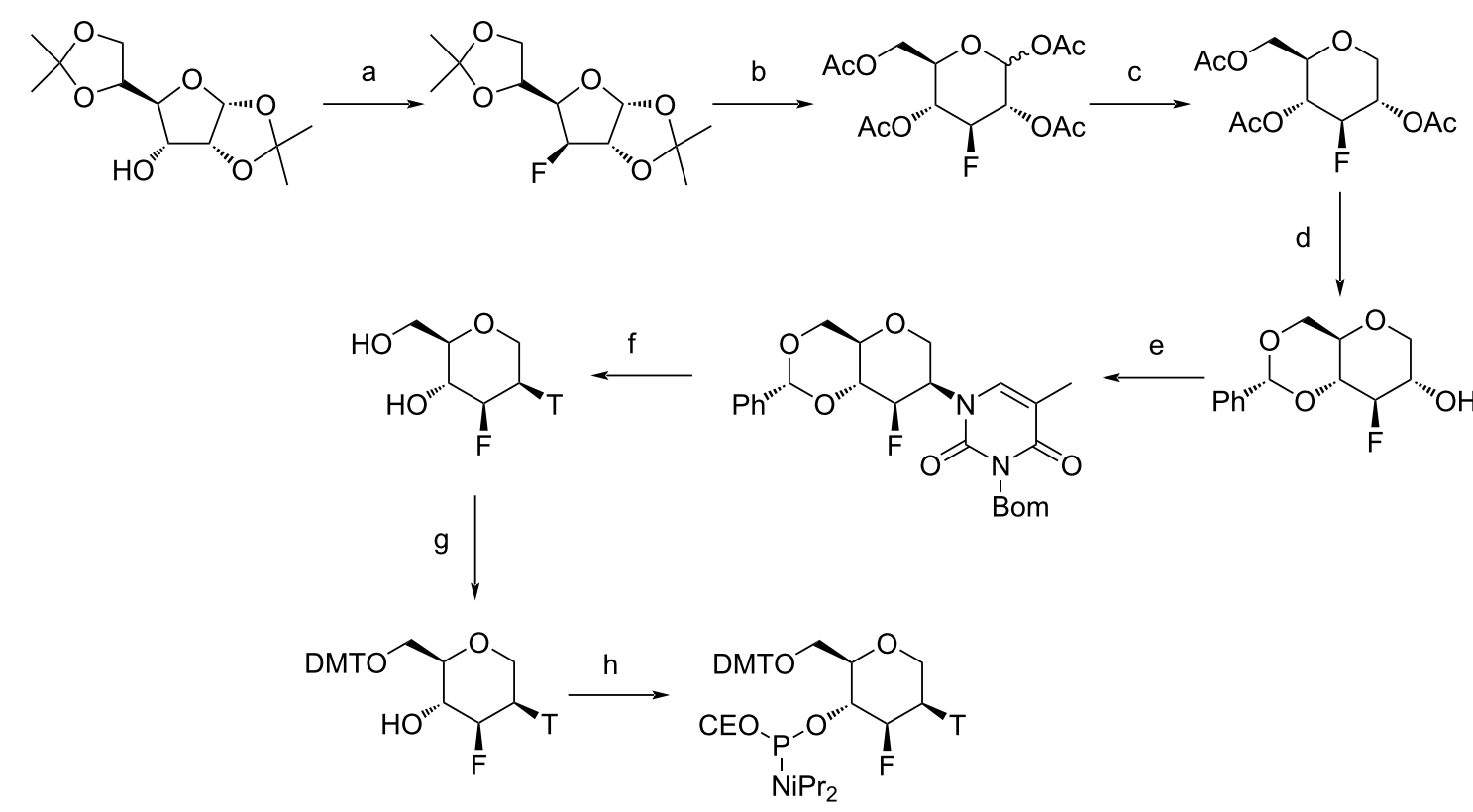

Scheme 10: Synthesis of the thymine Ara-FHNA phosphoramidite. (a) i) trifluoromethanesulfonic anhydride, pyridine, ii) CsF, tert-butanol; (b) i) Amberlite IR-120-H, 1,4-dioxane, water, ii) acetic anhydride, pyridine; (c) i) 33\% HBr in acetic acid, dichloromethane, ii) tributyltin hydride, 2,2'azobis(2-methylpropionitrile), toluene; (d) i) $\mathrm{K}_{2} \mathrm{CO}_{3}$, methanol, ii) benzaldehyde dimethyl acetal, $p$-toluenesulfonic acid, DMF; (e) i) trifluoromethanesulfonic anhydride, dichloromethane, pyridine, ii) N3-benzyloxymethylthymine, 1,8-diazabicyclo[5.4.0]undec-7-ene, dimethyl sulfoxide; (f) $\mathrm{H}_{2}$, $\mathrm{Pd}(\mathrm{OH})_{2} / \mathrm{C}$, methanol; (g) DMTCl, pyridine; (h) $\mathrm{P}\left(\mathrm{NiPr}_{2}\right)_{2}(\mathrm{OCE}), 1 \mathrm{H}$-tetrazole, NMI, DMF. Bom = benzyloxymethyl. Adapted from [221].

FHNA (Figure 10A) leads to stabilization of the resulting nucleic acid duplex, whereas the incorporation of ara-FHNA leads to sequence-dependent destabilization of the duplex [221]. The FHNA modification is better at discerning G-T mismatches than DNA or LNA, and both FHNA and Ara-FHNA were more stable against exonuclease digestion in comparison to LNA and MOE-modified oligonucleotides [221]. X-ray crystallographic studies showed that the equatorial 3'-fluorine of Ara-FHNA-T in the A-form DNA decamer pushes away $\mathrm{O} 4$ ' from the 3'-adja- cent 2'-deoxy-A within the minor groove of the duplex [221] (Figure 10B). To avoid a clash between the Ara-FHNA hexose and the 3 -adjacent deoxyribose, the duplex undergoes a slight conformational change that results in partial unstacking of the thymine and adenine bases [221], explaining the lower RNA affinity of Ara-FHNA compared to FHNA. Further experiments in vivo also demonstrated the effectiveness of FHNAmodified siRNA in the downregulation of mouse phosphatase and tensin homologue (PTEN) without inducing hepatotoxicity 


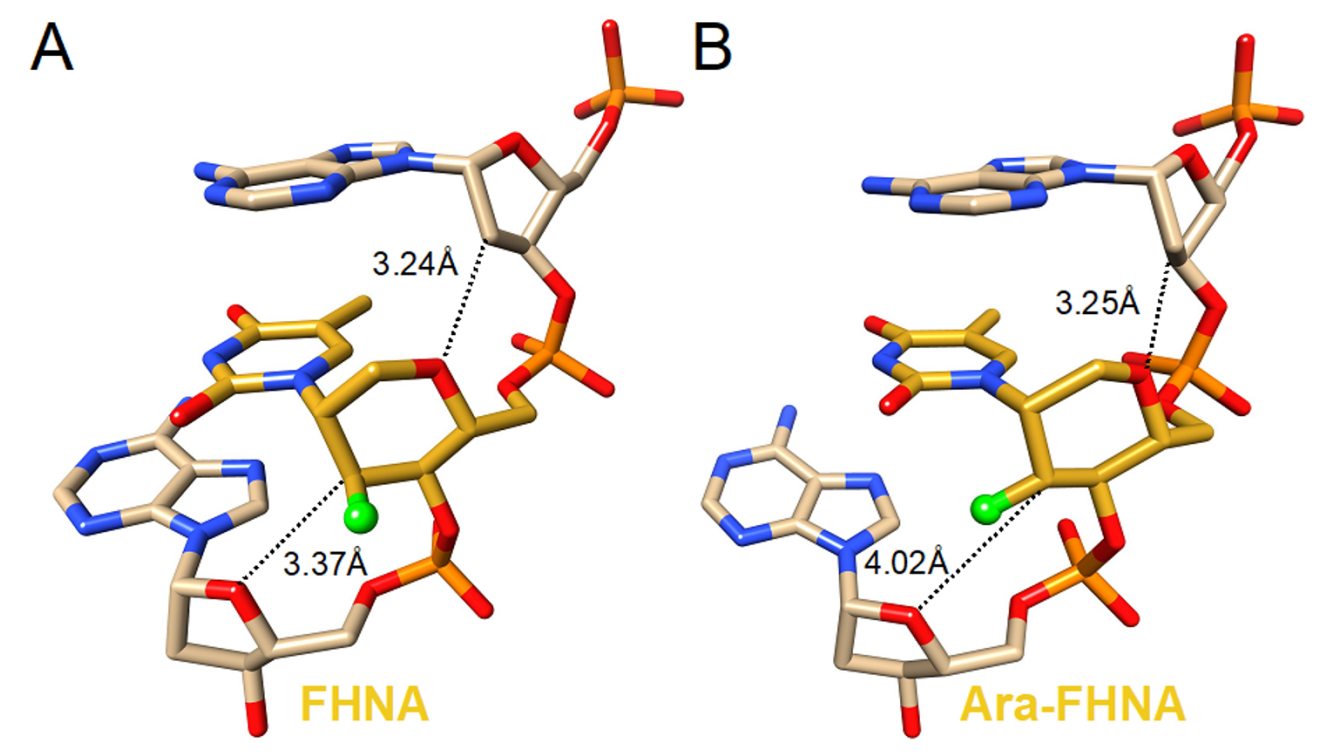

Figure 10: Crystal structures of (A) FHNA and (B) Ara-FHNA in modified A-form DNA decamers (PDB IDs 3Q61 and 3SD8, respectively) [221]. Unlike the trans-diaxial orientation of the fluorine in FHNA, the equatorial orientation of fluorine in Ara-FHNA pushes away the 3'-adjacent nucleotide (dashed lines) and causes local unstacking of bases.

[221]. Recent work has also shown that FHNA modifications improve the potency of GalNAc-conjugated gapmer ASOs [226].

Methylation at the C6' position further influences the RNA affinity of nucleic acids containing these modifications. R-6'Me-FHNA is highly destabilizing, whereas $S$-6'-Me-FHNA leads to duplex stabilization [227]. This trend is identical to the C5' methylation of LNA [228]. The $1.24 \AA$ crystal structures of A-form decamer duplexes containing these C6'-methylations show a small 1-5 intranucleoside contact between the C6 methyl group and the O4' in $R$-6'-Me-FHNA [227]. Additionally, $R$-6'-Me-FHNA perturbs the structure of water surrounding the $\mathrm{O} 2 \mathrm{P}$ atoms which will further reduce the pairing affinity of the $R$ isomer [227].

Herdewijn recently published the synthesis of 4'-aminotritylhexitol nucleosides for the eventual synthesis of N4' $\rightarrow$ P6' phosphoramidates of aminohexitol nucleic acids (AHNA) [229], as well as the synthesis of 3'-fluoro-4'-aminohexitol nucleosides which contain both the $3^{\prime}$-fluoro functionality and the N4' $\rightarrow$ P6' phosphoramidate linkage [230].

\section{Ribo-difluorotoluyl}

2'-Deoxydifluorotoluyl (dF) nucleoside derivatives (Figure 1J) were first synthesized by Schweitzer and Kool in 1994 in order to study the importance of H-bonding and base stacking in DNA. Specifically, they focused on the 2,4-difluorotoluene moiety as an isostere of the natural thymine base, albeit without the ability to form H-bonds [231]. A few years later, in 1997, Moran et al. showed that $\mathrm{dF}$ was a good template for enzymatic DNA synthesis, permitting production of the complementary DNA strand and hence suggesting that shape complementarity may be more important than H-bonding for fidelity and efficiency of DNA polymerases [232,233]. Recently, the rF nucleoside analogue has been investigated for its ability to efficiently silence gene expression when incorporated into short interfering RNA (siRNA) duplexes and to further investigate the fidelity of various RNA polymerases [234-236]. siRNA guide strands modified at the 5 ' end with $\mathrm{rF}$ showed similar silencing to the unmodified control. Furthermore, internal $\mathrm{rF}$ modifications showed lower affinity for their target but exhibited higher nuclease resistance [235,237]. Moreover, the $\mathrm{rF} / \mathrm{A}$ pair lowers the $T_{\mathrm{m}}$ of the siRNA duplex but is less destabilizing than a mismatch (A/A, C/A and G/A) [235]. Several crystal structures of oligonucleotides containing the $\mathrm{dF}$ or $\mathrm{rF}$ nucleoside analogue alone and oligos with $\mathrm{dF}$ bound to DNA polymerases have been determined [235,237-240]. The $1.6 \AA$ resolution structure of the Dickerson-Drew dodecamer (DDD) with $\mathrm{dF}$ replacing T8 (i.e., dCGCGAATFCGCG), solved with crystals of the duplex grown in the presence of Bacillus halodurans RNase $\mathrm{H}$ (which was bound to the duplex but did not exert an influence on its structure), revealed distances of 3.09 and $3.12 \AA$ for the $\mathrm{F}^{4}(\mathrm{dF}) \cdots \mathrm{N}^{6}(\mathrm{~A})$ atoms of the two $\mathrm{dF}$ : A pairs similar to the $\mathrm{O}^{4}(\mathrm{~T}) \cdots \mathrm{N}^{6}(\mathrm{~A})$ distance $(2.96$ and $3.11 \AA$ ) observed for the native DDD [240]. The 1.6 A crystal structure of a duplex 
containing the $\mathrm{rF}$ analog ([rCGCFAAUUAGCG $]_{2}$ ) revealed a $\mathrm{F}^{4}(\mathrm{rF}) \cdots \mathrm{N}^{6}(\mathrm{~A})$ distance of approximately 4 A between the $\mathrm{rF}: \mathrm{A}$ pairs [235].

\section{Conclusion}

Chemically modified oligonucleotides have come of age as a class of therapeutic agents for a number of diseases. Taking inspiration from the structure, properties and biological roles of nucleic acids, scientists have employed chemistry to prepare a diverse collection of modifications to the architecture of this molecule imbuing desirable characteristics for applications as a therapeutic agent. In addition, many nucleic acid analogs have been explored for additional studies including investigation of artificial genetic systems, catalysts, and sensors. Amongst the oligonucleotide-based therapeutics that have been approved as drugs, the dominating modifications are the phosphorothioate backbone and at the $\mathrm{C} 2$ '-position (of ribose) including 2'-OMe, $2 '-\mathrm{F}$, and 2'-O-MOE. Moreover, combinations of these modifications in an oligonucleotide leads to a synergistic effect enhancing their therapeutic properties. Such combinations of nucleotide and backbone modifications with numerous analogs that have been developed will continue as an exciting direction for the next generation of oligonucleotide-based therapeutics. Rational design of future modifications with improved properties may be gleaned from insights from structural techniques. For example, stability, gene silencing and structural studies of chemically modified oligonucleotides containing fluorine at the sugar and nucleobase have provided insights into the role of noncovalent interactions on the properties of these molecules. The partnership between organic synthesis, biophysical chemistry, biochemistry and structural biology continues to guide the design and drive the achievements for oligonucleotide-based therapeutics.

\section{Acknowledgements}

The authors are grateful to the numerous co-workers and collaborators, from academia and industry, with whom we have worked over the years.

\section{Funding}

We thank the Natural Sciences and Engineering Research Council of Canada (Grant No. RGPIN-2017-06683 to C.J.W.), Alnylam Pharmaceuticals Inc. Cambridge, MA (M.E.) and the US National Institutes of Health for financial support (Grants No. NIH P01 CA160032, R01 ES026966 and R01 ES029357 to M.E.). C.L. is the recipient of a NSERC Alexander Graham Bell Canada Graduate Scholarship - Doctoral (CGS-D) and Miriam Aaron Roland Graduate Fellowship. K.D. is the recipient of a NSERC Postgraduate Scholarship - Master's (PGS-M) and a Hydro-Quebec Master's Scholarship. G.J. is a trainee of the NSERC Collaborative Research and Training Experience
Program in Programmed Molecules for Therapeutics, Sensing and Diagnostics (PROMOTE) and a recipient of a Concordia Merit Scholarship.

\section{ORCID ${ }^{\circledR}$ iDs}

Christopher Liczner - https://orcid.org/0000-0002-1741-0159

Martin Egli - https://orcid.org/0000-0003-4145-356X

Christopher J. Wilds - https://orcid.org/0000-0002-0336-4753

\section{References}

1. Sood, A. J.; Viner, C.; Hoffman, M. M. J. Cheminf. 2019, 11, 30. doi:10.1186/s13321-019-0349-4

2. Boccaletto, P.; Machnicka, M. A.; Purta, E.; Piątkowski, P.; Bagiński, B.; Wirecki, T. K.; de Crécy-Lagard, V.; Ross, R.; Limbach, P. A.; Kotter, A.; Helm, M.; Bujnicki, J. M. Nucleic Acids Res. 2018, 46, D303-D307. doi:10.1093/nar/gkx1030

3. Wagner, M.; Steinbacher, J.; Kraus, T. F. J.; Michalakis, S.; Hackner, B.; Pfaffeneder, T.; Perera, A.; Müller, M.; Giese, A.; Kretzschmar, H. A.; Carell, T. Angew. Chem., Int. Ed. 2015, 54, 12511-12514. doi:10.1002/anie.201502722

4. Wang, L.; Chen, S.; Xu, T.; Taghizadeh, K.; Wishnok, J. S.; Zhou, X.; You, D.; Deng, Z.; Dedon, P. C. Nat. Chem. Biol. 2007, 3, 709-710. doi:10.1038/nchembio.2007.39

5. Kellner, S.; DeMott, M. S.; Cheng, C. P.; Russell, B. S.; Cao, B.; You, D.; Dedon, P. C. Nat. Chem. Biol. 2017, 13, 888-894. doi:10.1038/nchembio.2407

6. Wu, Y.; Tang, Y.; Dong, X.; Zheng, Y. Y.; Haruehanroengra, P.; Mao, S.; Lin, Q.; Sheng, J. ACS Chem. Biol. 2020, 15, 1301-1305. doi:10.1021/acschembio.0c00163

7. Züst, R.; Cervantes-Barragan, L.; Habjan, M.; Maier, R.; Neuman, B. W.; Ziebuhr, J.; Szretter, K. J.; Baker, S. C.; Barchet, W.; Diamond, M. S.; Siddell, S. G.; Ludewig, B.; Thiel, V. Nat. Immunol. 2011, 12, 137-143. doi:10.1038/ni.1979

8. Motorin, Y.; Marchand, V. Genes 2018, 9, 642. doi:10.3390/genes9120642

9. Elliott, B. A.; Ho, H.-T.; Ranganathan, S. V.; Vangaveti, S.; Ilkayeva, O.; Abou Assi, H.; Choi, A. K.; Agris, P. F.; Holley, C. L. Nat. Commun. 2019, 10, 3401. doi:10.1038/s41467-019-11375-7

10. Dimitrova, D. G.; Teysset, L.; Carré, C. Genes 2019, 10, 117. doi:10.3390/genes10020117

11. Freier, S. M.; Altmann, K.-H. Nucleic Acids Res. 1997, 25, 4429-4443. doi:10.1093/nar/25.22.4429

12. Manoharan, M. Biochim. Biophys. Acta, Gene Struct. Expression 1999, 1489, 117-130. doi:10.1016/s0167-4781(99)00138-4

13. Manoharan, M.; Rajeev, K. G. Utilizing Chemistry to Harness RNA Interference Pathways for Therapeutics: Chemically Modified siRNAs and Antagomirs. In Antisense Drug Technology, 2nd ed.; Crooke, S. T., Ed.; CRC Press: Boca Raton, FL, USA, 2008; pp 437-464.

14. Ni, S.; Yao, H.; Wang, L.; Lu, J.; Jiang, F.; Lu, A.; Zhang, G. Int. J. Mol. Sci. 2017, 18, 1683. doi:10.3390/ijms18081683

15. Egli, M.; Manoharan, M. Acc. Chem. Res. 2019, 52, 1036-1047. doi:10.1021/acs.accounts.8b00650

16. Yamasaki, K.; Akutsu, Y.; Yamasaki, T.; Miyagishi, M.; Kubota, T. Nucleic Acids Res. 2020, 48, 4551-4561. doi:10.1093/nar/gkaa170 
17. Hyjek-Składanowska, M.; Vickers, T. A.; Napiórkowska, A.; Anderson, B. A.; Tanowitz, M.; Crooke, S. T.; Liang, X.-h.; Seth, P. P.; Nowotny, M. J. Am. Chem. Soc. 2020, 142, 7456-7468. doi:10.1021/jacs.9b13524

18. Shen, X.; Corey, D. R. Nucleic Acids Res. 2018, 46, 1584-1600. doi:10.1093/nar/gkx1239

19. Crooke, S. T.; Witztum, J. L.; Bennett, C. F.; Baker, B. F. Cell Metab. 2018, 27, 714-739. doi:10.1016/j.cmet.2018.03.004

20. Roberts, T. C.; Langer, R.; Wood, M. J. A. Nat. Rev. Drug Discovery 2020, 19, 673-694. doi:10.1038/s41573-020-0075-7

21. Egli, M.; Manoharan, M. Nucleic Acids Res. submitted.

22. Furukawa, Y.; Kobayashi, K.; Kanai, Y.; Honjo, M. Chem. Pharm. Bull. 1965, 13, 1273-1278. doi:10.1248/cpb.13.1273

23. Eckstein, F. J. Am. Chem. Soc. 1966, 88, 4292-4294. doi:10.1021/ja00970a054

24. Codington, J. F.; Doerr, I.; Van Praag, D.; Bendich, A.; Fox, J. J. J. Am. Chem. Soc. 1961, 83, 5030-5031. doi:10.1021/ja01485a036

25. Westheimer, F. Science 1987, 235, 1173-1178. doi:10.1126/science. 2434996

26. Kamerlin, S. C. L.; Sharma, P. K.; Prasad, R. B.; Warshel, A. Q. Rev. Biophys. 2013, 46, 1-132. doi:10.1017/s0033583512000157

27. Rich, A. Nat. Struct. Mol. Biol. 2003, 10, 247-249. doi:10.1038/nsb0403-247

28. Egli, M. Sugar Pucker and Nucleic Acid Structure. In The Excitement of Discovery: Selected Papers of Alexander Rich: A Tribute to Alexander Rich; Zhang, S., Ed.; Series in Structural Biology; World Scientific Publishers: Singapore, 2018; pp 309-315. doi:10.1142/9789813272682_others05

29. Tamura, M.; Holbrook, S. R. J. Mol. Biol. 2002, 320, 455-474 doi:10.1016/s0022-2836(02)00515-6

30. Butcher, S. E.; Pyle, A. M. Acc. Chem. Res. 2011, 44, 1302-1311. doi:10.1021/ar200098t

31. Denning, E. J.; MacKerell, A. D., Jr. J. Am. Chem. Soc. 2012, 134, 2800-2806. doi:10.1021/ja211328g

32. Darré, L.; Ivani, I.; Dans, P. D.; Gómez, H.; Hospital, A.; Orozco, M. J. Am. Chem. Soc. 2016, 138, 16355-16363. doi:10.1021/jacs.6b09471

33. Shi, Y. Nat. Rev. Mol. Cell Biol. 2017, 18, 655-670. doi:10.1038/nrm.2017.86

34. Fica, S. M.; Nagai, K. Nat. Struct. Mol. Biol. 2017, 24, 791-799. doi:10.1038/nsmb.3463

35. Peebles, C. L.; Perlman, P. S.; Mecklenburg, K. L.; Petrillo, M. L.; Tabor, J. H.; Jarrell, K. A.; Cheng, H.-L. Cell 1986, 44, 213-223. doi:10.1016/0092-8674(86)90755-5

36. Qin, P. Z.; Pyle, A. M. Curr. Opin. Struct. Biol. 1998, 8, 301-308. doi:10.1016/s0959-440x(98)80062-6

37. Cech, T. Science 1987, 236, 1532-1539. doi:10.1126/science.2438771

38. Emilsson, G. M.; Nakamura, S.; Roth, A.; Breaker, R. R. RNA 2003, 9, 907-918. doi:10.1261/rna.5680603

39. O'Rourke, S. M.; Scott, W. G. Prog. Mol. Biol. Transl. Sci. 2018, 159, 177-202. doi:10.1016/bs.pmbts.2018.07.006

40. Egli, M.; Lubini, P.; Pallan, P. S. Chem. Soc. Rev. 2007, 36, 31-45. doi:10.1039/b606807c

41. Egli, M.; Minasov, G.; Tereshko, V.; Pallan, P. S.; Teplova, M.; Inamati, G. B.; Lesnik, E. A.; Owens, S. R.; Ross, B. S.; Prakash, T. P.; Manoharan, M. Biochemistry 2005, 44, 9045-9057. doi:10.1021/bi050574m

42. Deleavey, G. F.; Damha, M. J. Chem. Biol. 2012, 19, 937-954. doi:10.1016/j.chembiol.2012.07.011
43. Seth, P. P.; Swayze, E. E. Unnatural Nucleoside Analogs for Antisense Therapy. In Natural Products in Medicinal Chemistry; Hanessian, S., Ed.; Wiley-VCH: Weinheim, Germany, 2014; Vol. 60, pp 403-440. doi:10.1002/9783527676545.ch12

44. Campbell, M. A.; Wengel, J. Chem. Soc. Rev. 2011, 40, 5680-5689. doi:10.1039/c1cs15048k

45. Kotikam, V.; Rozners, E. Acc. Chem. Res. 2020, 53, 1782-1790. doi:10.1021/acs.accounts.0c00249

46. Wan, W. B.; Migawa, M. T.; Vasquez, G.; Murray, H. M.; Nichols, J. G.; Gaus, H.; Berdeja, A.; Lee, S.; Hart, C. E.; Lima, W. F.; Swayze, E. E.; Seth, P. P. Nucleic Acids Res. 2014, 42, 13456-13468. doi:10.1093/nar/gku1115

47. Iwamoto, N.; Butler, D. C. D.; Svrzikapa, N.; Mohapatra, S.; Zlatev, I.; Sah, D. W. Y.; Meena; Standley, S. M.; Lu, G.; Apponi, L. H.; Frank-Kamenetsky, M.; Zhang, J. J.; Vargeese, C.; Verdine, G. L. Nat. Biotechnol. 2017, 35, 845-851. doi:10.1038/nbt.3948

48. Schöning, K.-U.; Scholz, P.; Guntha, S.; Wu, X.; Krishnamurthy, R.; Eschenmoser, A. Science 2000, 290, 1347-1351. doi:10.1126/science.290.5495.1347

49. Maier, T.; Przylas, I.; Strater, N.; Herdewijn, P.; Saenger, W. J. Am. Chem. Soc. 2005, 127, 2937-2943. doi:10.1021/ja045843v

50. Kumar, P.; Degaonkar, R.; Guenther, D. C.; Abramov, M.; Schepers, G.; Capobianco, M.; Jiang, Y.; Harp, J.; Kaittanis, C.; Janas, M. M.; Castoreno, A.; Zlatev, I.; Schlegel, M. K.; Herdewijn, P.; Egli, M.; Manoharan, M. Nucleic Acids Res. 2020, 48, 4028-4040. doi:10.1093/nar/gkaa125

51. Maiti, M.; Maiti, M.; Knies, C.; Dumbre, S.; Lescrinier, E.; Rosemeyer, H.; Ceulemans, A.; Herdewijn, P. Nucleic Acids Res. 2015, 43, 7189-7200. doi:10.1093/nar/gkv719

52. Ovaere, M.; Herdewijn, P.; Van Meervelt, L. Chem. - Eur. J. 2011, 17, 7823-7830. doi:10.1002/chem.201003594

53. Moulton, H. M.; Moulton, J. D., Eds. Morpholino Oligomers; Methods in Molecular Biology, Vol. 1565; Humana Press, 2017. doi:10.1007/978-1-4939-6817-6

54. Schlegel, M. K.; Foster, D. J.; Kel'in, A. V.; Zlatev, I.; Bisbe, A.; Jayaraman, M.; Lackey, J. G.; Rajeev, K. G.; Charissé, K.; Harp, J.; Pallan, P. S.; Maier, M. A.; Egli, M.; Manoharan, M.

J. Am. Chem. Soc. 2017, 139, 8537-8546. doi:10.1021/jacs.7b02694

55. Anosova, I.; Kowal, E. A.; Dunn, M. R.; Chaput, J. C.; Van Horn, W. D.; Egli, M. Nucleic Acids Res. 2016, 44, 1007-1021. doi:10.1093/nar/gkv1472

56. Devine, K. G.; Jheeta, S. Life 2020, 10, 346. doi:10.3390/life10120346

57. Eriksson, M.; Nielsen, P. E. Q. Rev. Biophys. 1996, 29, 369-394. doi:10.1017/s0033583500005886

58. Teplova, M.; Minasov, G.; Tereshko, V.; Inamati, G. B.; Cook, P. D.; Manoharan, M.; Egli, M. Nat. Struct. Biol. 1999, 6, 535-539. doi:10.1038/9304

59. Crooke, S. T.; Baker, B. F.; Kwoh, T. J.; Cheng, W.; Schulz, D. J.; Xia, S.; Salgado, N.; Bui, H.-H.; Hart, C. E.; Burel, S. A.; Younis, H. S.; Geary, R. S.; Henry, S. P.; Bhanot, S. Mol. Ther. 2016, 24 , 1771-1782. doi:10.1038/mt.2016.136

60. Koch, T. Curr. Phys. Chem. 2013, 3, 55-68. doi:10.2174/1877946811303010009

61. Manoharan, M.; Akinc, A.; Pandey, R. K.; Qin, J.; Hadwiger, P.; John, M.; Mills, K.; Charisse, K.; Maier, M. A.; Nechev, L.; Greene, E. M.; Pallan, P. S.; Rozners, E.; Rajeev, K. G.; Egli, M. Angew. Chem., Int. Ed. 2011, 50, 2284-2288. doi:10.1002/anie.201006519 
62. Pallan, P. S.; Greene, E. M.; Jicman, P. A.; Pandey, R. K.; Manoharan, M.; Rozners, E.; Egli, M. Nucleic Acids Res. 2011, 39, 3482-3495. doi:10.1093/nar/gkq1270

63. Patra, A.; Paolillo, M.; Charisse, K.; Manoharan, M.; Rozners, E.; Egli, M. Angew. Chem., Int. Ed. 2012, 51, 11863-11866. doi:10.1002/anie.201204946

64. Gryaznov, S.; Chen, J.-K. J. Am. Chem. Soc. 1994, 116, 3143-3144. doi:10.1021/ja00086a062

65. Gryaznov, S. M.; Lloyd, D. H.; Chen, J. K.; Schultz, R. G.; DeDionisio, L. A.; Ratmeyer, L.; Wilson, W. D. Proc. Natl. Acad. Sci. U. S. A. 1995, 92, 5798-5802. doi:10.1073/pnas.92.13.5798

66. Chen, J.-K.; Schultz, R. G.; Lioyd, D. H.; Gryaznov, S. M. Nucleic Acids Res. 1995, 23, 2661-2668. doi:10.1093/nar/23.14.2661

67. Skorski, T.; Perrotti, D.; Nieborowska-Skorska, M.; Gryaznov, S.; Calabretta, B. Proc. Natl. Acad. Sci. U. S. A. 1997, 94, 3966-3971. doi:10.1073/pnas.94.8.3966

68. Heidenreich, O.; Gryaznov, S.; Nerenberg, M. Nucleic Acids Res. 1997, 25, 776-780. doi:10.1093/nar/25.4.776

69. Giovannangeli, C.; Diviacco, S.; Labrousse, V.; Gryaznov, S.; Charneau, P.; Helene, C. Proc. Natl. Acad. Sci. U. S. A. 1997, 94, 79-84. doi:10.1073/pnas.94.1.79

70. Rigl, C. T.; Lloyd, D. H.; Tsou, D. S.; Gryaznov, S. M.; Wilson, W. D. Biochemistry 1997, 36, 650-659. doi:10.1021/bi961980w

71. Tereshko, V.; Gryaznov, S.; Egli, M. J. Am. Chem. Soc. 1998, 120, 269-283. doi:10.1021/ja971962h

72. Escude, C.; Giovannangeli, C.; Sun, J. S.; Lloyd, D. H.; Chen, J. K.; Gryaznov, S. M.; Garestier, T.; Helene, C. Proc. Natl. Acad. Sci. U. S. A. 1996, 93, 4365-4369. doi:10.1073/pnas.93.9.4365

73. Mutisya, D.; Hardcastle, T.; Cheruiyot, S. K.; Pallan, P. S.; Kennedy, S. D.; Egli, M.; Kelley, M. L.; van Brabant Smith, A.; Rozners, E. Nucleic Acids Res. 2017, 45, 8142-8155. doi:10.1093/nar/gkx558

74. Wilds, C. J.; Minasov, G.; Natt, F.; von Matt, P.; Altmann, K.-H.; Egli, M. Nucleosides, Nucleotides Nucleic Acids 2001, 20, 991-994. doi: $10.1081 /$ ncn-100002475

75. Mutisya, D.; Selvam, C.; Lunstad, B. D.; Pallan, P. S.; Haas, A.; Leake, D.; Egli, M.; Rozners, E. Nucleic Acids Res. 2014, 42, 6542-6551. doi:10.1093/nar/gku235

76. Idziak, I.; Just, G.; Damha, M. J.; Giannaris, P. A. Tetrahedron Lett. 1993, 34, 5417-5420. doi:10.1016/s0040-4039(00)73923-2

77. Rozners, E.; Katkevica, D.; Bizdena, E.; Strömberg, R. J. Am. Chem. Soc. 2003, 125, 12125-12136. doi:10.1021/ja0360900

78. von Matt, P.; De Mesmaeker, A.; Pieles, U.; Zürcher, W.; Altmann, K.-H. Tetrahedron Lett. 1999, 40, 2899-2902. doi:10.1016/s0040-4039(99)00389-5

79. Selvam, C.; Thomas, S.; Abbott, J.; Kennedy, S. D.; Rozners, E. Angew. Chem., Int. Ed. 2011, 50, 2068-2070. doi:10.1002/anie.201007012

80. Iwase, R.; Kurokawa, R.; Ueno, J. Nucleic Acids Symp. Ser. 2009, 53, 119-120. doi:10.1093/nass/nrp060

81. Epple, S.; Thorpe, C.; Baker, Y. R.; El-Sagheer, A. H.; Brown, T. Chem. Commun. 2020, 56, 5496-5499. doi:10.1039/d0cc00444h

82. Elkayam, E.; Kuhn, C.-D.; Tocilj, A.; Haase, A. D.; Greene, E. M.; Hannon, G. J.; Joshua-Tor, L. Cell 2012, 150, 100-110. doi:10.1016/j.cell.2012.05.017
83. Hardcastle, T.; Novosjolova, I.; Kotikam, V.; Cheruiyot, S. K.; Mutisya, D.; Kennedy, S. D.; Egli, M.; Kelley, M. L.; Smith, A. v. B.; Rozners, E. ACS Chem. Biol. 2018, 13, 533-536. doi:10.1021/acschembio.7b01012

84. Beaton, G.; Brill, W. K.-D.; Grandas, A.; Ma, Y.-X.; Nielsen, J.; Yau, E.; Caruthers, M. H. Tetrahedron 1991, 47, 2377-2388. doi:10.1016/s0040-4020(01)81775-0

85. Marshall, W.; Caruthers, M. Science 1993, 259, 1564-1570. doi:10.1126/science.7681216

86. Iyer, R. P.; Egan, W.; Regan, J. B.; Beaucage, S. L. J. Am. Chem. Soc. 1990, 112, 1253-1254. doi:10.1021/ja00159a059

87. Wickstrom, E. Adv. Drug Delivery Rev. 2015, 87, 25-34. doi:10.1016/j.addr.2015.04.012

88. Clavé, G.; Reverte, M.; Vasseur, J.-J.; Smietana, M. RSC Chem. Biol. 2021, 2, 94-150. doi:10.1039/d0cb00136h

89. Pallan, P. S.; Lybrand, T. P.; Schlegel, M. K.; Harp, J. M.; Jahns, H.; Manoharan, M.; Egli, M. Biochemistry 2020, 59, 4627-4637. doi:10.1021/acs.biochem.0c00685

90. Caruthers, M. H. Acc. Chem. Res. 1991, 24, 278-284. doi:10.1021/ar00009a005

91. Yang, X.; Sierant, M.; Janicka, M.; Peczek, L.; Martinez, C.; Hassell, T.; Li, N.; Li, X.; Wang, T.; Nawrot, B. ACS Chem. Biol. 2012, 7, 1214-1220. doi:10.1021/cb300078e

92. Pallan, P. S.; Yang, X.; Sierant, M.; Abeydeera, N. D.; Hassell, T.; Martinez, C.; Janicka, M.; Nawrot, B.; Egli, M. RSC Adv. 2014, 4, 64901-64904. doi:10.1039/c4ra10986d

93. Wu, S. Y.; Yang, X.; Gharpure, K. M.; Hatakeyama, H.; Egli, M.; McGuire, M. H.; Nagaraja, A. S.; Miyake, T. M.; Rupaimoole, R.; Pecot, C. V.; Taylor, M.; Pradeep, S.; Sierant, M.; Rodriguez-Aguayo, C.; Choi, H. J.; Previs, R. A.; Armaiz-Pena, G. N.; Huang, L.; Martinez, C.; Hassell, T.; Ivan, C.; Sehgal, V.; Singhania, R.; Han, H.-D.; Su, C.; Kim, J. H.; Dalton, H. J.; Kovvali, C. Keyomarsi, K.; McMillan, N. A. J.; Overwijk, W. W.; Liu, J.; Lee, J.-S.; Baggerly, K. A.; Lopez-Berestein, G.; Ram, P. T.; Nawrot, B.; Sood, A. K. Nat. Commun. 2014, 5, 3459. doi:10.1038/ncomms4459

94. Egli, M.; Lybrand, T. P. J. Am. Chem. Soc. 2019, 141, 4445-4452. doi:10.1021/jacs.9b00104

95. Abeydeera, N. D.; Egli, M.; Cox, N.; Mercier, K.; Conde, J. N.; Pallan, P. S.; Mizurini, D. M.; Sierant, M.; Hibti, F.-E.; Hassell, T.; Wang, T.; Liu, F.-W.; Liu, H.-M.; Martinez, C.; Sood, A. K.; Lybrand, T. P.; Frydman, C.; Monteiro, R. Q.; Gomer, R. H.; Nawrot, B.; Yang, X. Nucleic Acids Res. 2016, 44, 8052-8064. doi:10.1093/nar/gkw725

96. Ueda, N.; Kawabata, T.; Takemoto, K. J. Heterocycl. Chem. 1971, 8, 827-829. doi:10.1002/jhet.5570080527

97. Seita, T.; Yamauchi, K.; Kinoshita, M.; Imoto, M. Makromol. Chem. 1972, 154, 255-261. doi:10.1002/macp.1972.021540123

98. Acevedo, O. L.; Andrews, R. S. Tetrahedron Lett. 1996, 37 , 3931-3934. doi:10.1016/0040-4039(96)00745-9

99. Zhang, L.; Peritz, A.; Meggers, E. J. Am. Chem. Soc. 2005, 127, 4174-4175. doi:10.1021/ja042564z

100.Chen, J. J.; Cai, X.; Szostak, J. W. J. Am. Chem. Soc. 2009, 131, 2119-2121. doi:10.1021/ja809069b

101.Schlegel, M. K.; Peritz, A. E.; Kittigowittana, K.; Zhang, L.; Meggers, E. ChemBioChem 2007, 8, 927-932. doi:10.1002/cbic.200600435

102. Tsai, C.-H.; Chen, J.; Szostak, J. W. Proc. Natl. Acad. Sci. U. S. A. 2007, 104, 14598-14603. doi:10.1073/pnas.0704211104

103. Meggers, E.; Zhang, L. Acc. Chem. Res. 2010, 43, 1092-1102. doi:10.1021/ar900292q 
104. Nielsen, P.; Dreiøe, L. H.; Wengel, J. Bioorg. Med. Chem. 1995, 3 , 19-28. doi:10.1016/0968-0896(94)00143-q

105.Schlegel, M. K.; Essen, L.-O.; Meggers, E. J. Am. Chem. Soc. 2008, 130, 8158-8159. doi:10.1021/ja802788g

106.Johnson, A. T.; Schlegel, M. K.; Meggers, E.; Essen, L.-O.; Wiest, O. J. Org. Chem. 2011, 76, 7964-7974. doi:10.1021/jo201469b

107.Schlegel, M. K.; Essen, L.-O.; Meggers, E. Chem. Commun. 2010, 46, 1094-1096. doi:10.1039/b916851f

108. Inoue, H.; Hayase, Y.; Imura, A.; Iwai, S.; Miura, K.; Ohtsuka, E. Nucleic Acids Res. 1987, 15, 6131-6148. doi:10.1093/nar/15.15.6131

109. Ross, B. S.; Springer, R. H.; Tortorici, Z.; Dimock, S. Nucleosides Nucleotides 1997, 16, 1641-1643. doi:10.1080/07328319708006245

110.Beigelman, L.; Haeberli, P.; Sweedler, D.; Karpeisky, A. Tetrahedron 2000, 56, 1047-1056. doi:10.1016/s0040-4020(00)00002-8

111.Roy, S. K.; Tang, J.-y. Org. Process Res. Dev. 2000, 4, 170-171. doi:10.1021/op990100t

112.Cummins, L. L.; Owens, S. R.; Risen, L. M.; Lesnik, E. A.; Freier, S. M.; McGee, D.; Guinosso, C. J.; Cook, P. D. Nucleic Acids Res. 1995, 23, 2019-2024. doi:10.1093/nar/23.11.2019

113. Inoue, H.; Hayase, Y.; Iwai, S.; Ohtsuka, E. FEBS Lett. 1987, 215, 327-330. doi:10.1016/0014-5793(87)80171-0

114.Lubini, P.; Zürcher, W.; Egli, M. Chem. Biol. 1994, 1, 39-45. doi:10.1016/1074-5521(94)90039-6

115.Lesnik, E. A.; Guinosso, C. J.; Kawasaki, A. M.; Sasmor, H.; Zounes, M.; Cummins, L. L.; Ecker, D. J.; Cook, P. D.; Freier, S. M. Biochemistry 1993, 32, 7832-7838. doi:10.1021/bi00081a031

116. Martin, P. Helv. Chim. Acta 1995, 78, 486-504. doi:10.1002/hlca.19950780219

117.Legorburu, U.; Reese, C. B.; Song, Q. Tetrahedron 1999, 55, 5635-5640. doi:10.1016/s0040-4020(99)00229-x

118. Chow, S.; Wen, K.; Sanghvi, Y. S.; Theodorakis, E. A. Nucleosides, Nucleotides Nucleic Acids 2003, 22, 583-587. doi:10.1081/ncn-120021959

119.Altmann, K.-H.; Fabbro, D.; Dean, N. M.; Geiger, T.; Monia, B. P.; Müllert, M.; Nicklin, P. Biochem. Soc. Trans. 1996, 24, 630-637. doi:10.1042/bst0240630

120.Tereshko, V.; Portmann, S.; Tay, E. C.; Martin, P.; Natt, F.; Altmann, K.-H.; Egli, M. Biochemistry 1998, 37, 10626-10634. doi:10.1021/bi980392a

121. Prakash, T. P. Chem. Biodiversity 2011, 8, 1616-1641. doi:10.1002/cbdv.201100081

122.Stephenson, M. L.; Zamecnik, P. C. Proc. Natl. Acad. Sci. U. S. A. 1978, 75, 285-288. doi:10.1073/pnas.75.1.285

123.Barabino, S. M. L.; Blencowe, B. J.; Ryder, U.; Sproat, B. S.; Lamond, A. I. Cell 1990, 63, 293-302. doi:10.1016/0092-8674(90)90162-8

124. Iribarren, A. M.; Sproat, B. S.; Neuner, P.; Sulston, I.; Ryder, U.; Lamond, A. I. Proc. Natl. Acad. Sci. U. S. A. 1990, 87, 7747-7751. doi:10.1073/pnas.87.19.7747

125.Boiziau, C.; Larrouy, B.; Sproat, B. S.; Toulmè, J.-J. Nucleic Acids Res. 1995, 23, 64-71. doi:10.1093/nar/23.1.64

126. Obika, S.; Nanbu, D.; Hari, Y.; Morio, K.-i.; In, Y.; Ishida, T.; Imanishi, T. Tetrahedron Lett. 1997, 38, 8735-8738. doi:10.1016/s0040-4039(97)10322-7

127.Singh, S. K.; Koshkin, A. A.; Wengel, J.; Nielsen, P. Chem. Commun. 1998, 455-456. doi:10.1039/a708608c

128. Koshkin, A. A.; Singh, S. K.; Nielsen, P.; Rajwanshi, V. K.; Kumar, R.; Meldgaard, M.; Olsen, C. E.; Wengel, J. Tetrahedron 1998, 54, 3607-3630. doi:10.1016/s0040-4020(98)00094-5
129. Nielsen, C. B.; Singh, S. K.; Wengel, J.; Jacobsen, J. P. J. Biomol. Struct. Dyn. 1999, 17, 175-191. doi:10.1080/07391102.1999.10508352

130. Braasch, D. A.; Corey, D. R. Chem. Biol. 2001, 8, 1-7. doi:10.1016/s1074-5521(00)00058-2

131.Obika, S.; Nanbu, D.; Hari, Y.; Andoh, J.-i.; Morio, K.-i.; Doi, T.; Imanishi, T. Tetrahedron Lett. 1998, 39, 5401-5404. doi:10.1016/s0040-4039(98)01084-3

132. Petersen, M.; Wengel, J. Trends Biotechnol. 2003, 21, 74-81. doi:10.1016/s0167-7799(02)00038-0

133. Singh, S. K.; Wengel, J. Chem. Commun. 1998, 1247-1248. doi:10.1039/a801571f

134. Wengel, J. Acc. Chem. Res. 1999, 32, 301-310. doi:10.1021/ar980051p

135. Bondensgaard, K.; Petersen, M.; Singh, S. K.; Rajwanshi, V. K.; Kumar, R.; Wengel, J.; Jacobsen, J. P. Chem. - Eur. J. 2000, 6, 2687-2695. doi:10.1002/1521-3765(20000804)6:15<2687::aid-chem2687>3.0.co; 2-u

136. Petersen, M.; Bondensgaard, K.; Wengel, J.; Jacobsen, J. P. J. Am. Chem. Soc. 2002, 124, 5974-5982. doi:10.1021/ja012288d

137.Schmidt, K. S.; Borkowski, S.; Kurreck, J.; Stephens, A. W.; Bald, R.; Hecht, M.; Friebe, M.; Dinkelborg, L.; Erdmann, V. A. Nucleic Acids Res. 2004, 32, 5757-5765. doi:10.1093/nar/gkh862

138. Kaur, H.; Babu, B. R.; Maiti, S. Chem. Rev. 2007, 107, 4672-4697. doi:10.1021/cr050266u

139. Fluiter, K.; ten Asbroek, A. L. M. A.; de Wissel, M. B.; Jakobs, M. E.; Wissenbach, M.; Olsson, H.; Olsen, O.; Oerum, H.; Baas, F. Nucleic Acids Res. 2003, 31, 953-962. doi:10.1093/nar/gkg185

140. Grünweller, A.; Wyszko, E.; Bieber, B.; Jahnel, R.; Erdmann, V. A.; Kurreck, J. Nucleic Acids Res. 2003, 31, 3185-3193. doi:10.1093/nar/gkg409

141.Schubert, S.; Gül, D. C.; Grunert, H.-P.; Zeichhardt, H.; Erdmann, V. A.; Kurreck, J. Nucleic Acids Res. 2003, 31, 5982-5992. doi:10.1093/nar/gkg791

142. Kuespert, S.; Heydn, R.; Peters, S.; Wirkert, E.; Meyer, A.-L.; Siebörger, M.; Johannesen, S.; Aigner, L.; Bogdahn, U.; Bruun, T.-H. Int. J. Mol. Sci. 2020, 21, 1952. doi:10.3390/ijms21061952

143.van Ravesteyn, T. W.; Dekker, M.; Fish, A.; Sixma, T. K.; Wolters, A.; Dekker, R. J.; te Riele, H. P. J. Proc. Natl. Acad. Sci. U. S. A. 2016, 113, 4122-4127. doi:10.1073/pnas.1513315113

144.Ju, E.; Li, T.; Liu, Z.; da Silva, S. R.; Wei, S.; Zhang, X.; Wang, X.; Gao, S.-J. ACS Nano 2020, 14, 476-487. doi:10.1021/acsnano.9b06333

145. Fluiter, K.; Frieden, M.; Vreijling, J.; Rosenbohm, C.; De Wissel, M. B.; Christensen, S. M.; Koch, T.; Ørum, H.; Baas, F. ChemBioChem 2005, 6, 1104-1109. doi:10.1002/cbic.200400419

146. Rajwanshi, V. K.; Håkansson, A. E.; Dahl, B. M.; Wengel, J. Chem. Commun. 1999, 1395-1396. doi:10.1039/a903189h

147.Nielsen, K. M. E.; Petersen, M.; Håkansson, A. E.; Wengel, J.; Jacobsen, J. P. Chem. - Eur. J. 2002, 8, 3001-3009. doi:10.1002/1521-3765(20020703)8:13<3001::aid-chem3001>3.0.co; 2-1

148. Jørgensen, A. S.; Hansen, L. H.; Vester, B.; Wengel, J. Bioorg. Med. Chem. Lett. 2014, 24, 2273-2277. doi:10.1016/j.bmcl.2014.03.082

149. Raguraman, P.; Wang, T.; Ma, L.; Jørgensen, P. T.; Wengel, J.; Veedu, R. N. Int. J. Mol. Sci. 2020, 21, 2434. doi:10.3390/ijms21072434 
150.Singh, S. K.; Kumar, R.; Wengel, J. J. Org. Chem. 1998, 63, 10035-10039. doi:10.1021/jo9814445

151. Astakhova, I. K.; Wengel, J. Acc. Chem. Res. 2014, 47, 1768-1777. doi:10.1021/ar500014g

152.Rosenbohm, C.; Christensen, S. M.; Sørensen, M. D.; Pedersen, D. S.; Larsen, L.-E.; Wengel, J.; Koch, T. Org. Biomol. Chem. 2003, 1, 655-663. doi:10.1039/b208864a

153.Sørensen, M. D.; Petersen, M.; Wengel, J. Chem. Commun. 2003, 2130-2131. doi:10.1039/b307026c

154. Hrdlicka, P. J.; Babu, B. R.; Sørensen, M. D.; Wengel, J. Chem. Commun. 2004, 1478-1479. doi:10.1039/b404446k

155. Valeur, E.; Bradley, M. Chem. Soc. Rev. 2009, 38, 606-631. doi:10.1039/b701677h

156. Baxter, E. W.; Reitz, A. B. Reductive Aminations of Carbonyl Compounds with Borohydride and Borane Reducing Agents. Organic Reactions; John Wiley \& Sons, 2004; pp 1-714. doi:10.1002/0471264180.or059.01

157. Obika, S.; Onoda, M.; Morita, K.; Andoh, J.-i.; Koizumi, M.; Imanishi, T. Chem. Commun. 2001, 1992-1993. doi:10.1039/b105640a

158. Morihiro, K.; Kodama, T.; Kentefu; Moai, Y.; Veedu, R. N.; Obika, S. Angew. Chem., Int. Ed. 2013, 52, 5074-5078. doi:10.1002/anie.201300555

159. Moai, Y.; Hiroaki, H.; Obika, S.; Kodama, T. Nucleosides, Nucleotides Nucleic Acids 2020, 39, 131-140. doi:10.1080/15257770.2019.1675169

160.Xu, J.; Liu, Y.; Dupouy, C.; Chattopadhyaya, J. J. Org. Chem. 2009, 74, 6534-6554. doi:10.1021/jo901009w

161.Egli, M.; Minasov, G.; Teplova, M.; Kumar, R.; Wengel, J. Chem. Commun. 2001, 651-652. doi:10.1039/b009447।

162.Seth, P. P.; Siwkowski, A.; Allerson, C. R.; Vasquez, G.; Lee, S.; Prakash, T. P.; Kinberger, G.; Migawa, M. T.; Gaus, H.; Bhat, B.; Swayze, E. E. Nucleic Acids Symp. Ser. 2008, 52, 553-554. doi: $10.1093 /$ nass/nrn280

163.Seth, P. P.; Vasquez, G.; Allerson, C. A.; Berdeja, A.; Gaus, H.; Kinberger, G. A.; Prakash, T. P.; Migawa, M. T.; Bhat, B.; Swayze, E. E. J. Org. Chem. 2010, 75, 1569-1581. doi:10.1021/jo902560f

164.Blade, H.; Bradley, D.; Diorazio, L.; Evans, T.; Hayter, B. R.; Howell, G. P. J. Org. Chem. 2015, 80, 5337-5343. doi:10.1021/acs.joc.5b00607

165. Hong, D.; Kurzrock, R.; Kim, Y.; Woessner, R.; Younes, A.; Nemunaitis, J.; Fowler, N.; Zhou, T.; Schmidt, J.; Jo, M.; Lee, S. J.; Yamashita, M.; Hughes, S. G.; Fayad, L.; Piha-Paul, S.; Nadella, M. V. P.; Mohseni, M.; Lawson, D.; Reimer, C.; Blakey, D. C.; Xiao, X.; Hsu, J.; Revenko, A.; Monia, B. P.; MacLeod, A. R. Sci. Transl. Med. 2015, 7, 314ra185 doi:10.1126/scitranslmed.aac5272

166. Barman, J.; Gurav, D.; Oommen, O. P.; Varghese, O. P. RSC Adv. 2015, 5, 12257-12260. doi:10.1039/c4ra14721a

167.Mitsuoka, Y.; Aoyama, H.; Kugimiya, A.; Fujimura, Y.; Yamamoto, T.; Waki, R.; Wada, F.; Tahara, S.; Sawamura, M.; Noda, M.; Hari, Y.; Obika, S. Org. Biomol. Chem. 2016, 14, 6531-6538. doi:10.1039/c6ob01051b

168. Vejlegaard, K.; Wegeberg, C.; McKee, V.; Wengel, J. Org. Biomol. Chem. 2018, 16, 1312-1321. doi:10.1039/c7ob02663c

169.Seth, P. P.; Allerson, C. R.; Berdeja, A.; Siwkowski, A.; Pallan, P. S.; Gaus, H.; Prakash, T. P.; Watt, A. T.; Egli, M.; Swayze, E. E. J. Am. Chem. Soc. 2010, 132, 14942-14950. doi:10.1021/ja105875e
170. Ito, Y.; Tsutsui, N.; Osawa, T.; Hari, Y. J. Org. Chem. 2019, 84, 9093-9100. doi:10.1021/acs.joc.9b01035

171. Kumar, P.; El-Sagheer, A. H.; Truong, L.; Brown, T. Chem. Commun. 2017, 53, 8910-8913. doi:10.1039/c7cc05159j

172.Sharma, V. K.; Singh, S. K.; Krishnamurthy, P. M.; Alterman, J. F.; Haraszti, R. A.; Khvorova, A.; Prasad, A. K.; Watts, J. K. Chem. Commun. 2017, 53, 8906-8909. doi:10.1039/c7cc04092j

173.Seley-Radtke, K. L.; Yates, M. K. Antiviral Res. 2018, 154, 66-86. doi:10.1016/j.antiviral.2018.04.004

174. Fox, J. J. Pure Appl. Chem. 1969, 18, 223-256. doi:10.1351/pac196918010223

175. Glaudemans, C. P. J.; Fletcher, H. G., Jr. J. Org. Chem. 1963, 28 , 3004-3006. doi:10.1021/jo01046a016

176. Tann, C. H.; Brodfuehrer, P. R.; Brundidge, S. P.; Sapino, C., Jr.; Howell, H. G. J. Org. Chem. 1985, 50, 3644-3647. doi:10.1021/jo00219a048

177. Howell, H. G.; Brodfuehrer, P. R.; Brundidge, S. P.; Benigni, D. A.; Sapino, C., Jr. J. Org. Chem. 1988, 53, 85-88. doi:10.1021/jo00236a017

178. Wilds, C. J.; Damha, M. J. Nucleic Acids Res. 2000, 28, 3625-3635. doi:10.1093/nar/28.18.3625

179. Elzagheid, M. I.; Viazovkina, E.; Damha, M. J. Curr. Protoc. Nucleic Acid Chem. 2002, 10, 1.7.1-1.7.19. doi:10.1002/0471142700.nc0107s10

180. Elzagheid, M. I.; Viazovkina, E.; Damha, M. J. Nucleosides, Nucleotides Nucleic Acids 2003, 22, 1339-1342. doi:10.1081/ncn-120022960

181.Damha, M. J.; Usman, N.; Ogilvie, K. K. Can. J. Chem. 1989, 67, 831-839. doi:10.1139/v89-129

182. Giannaris, P. A.; Damha, M. J. Can. J. Chem. 1994, 72, 909-918. doi:10.1139/v94-118

183. Noronha, A. M.; Wilds, C. J.; Lok, C.-N.; Viazovkina, K.; Arion, D.; Parniak, M. A.; Damha, M. J. Biochemistry 2000, 39, 7050-7062. doi:10.1021/bi000280v

184. Viazovkina, E.; Mangos, M. M.; Elzagheid, M. I.; Damha, M. J. Curr. Protoc. Nucleic Acid Chem. 2002, 10, 4.15.1-4.15.22. doi:10.1002/0471142700.nc0415s10

185. Kawasaki, A. M.; Casper, M. D.; Freier, S. M.; Lesnik, E. A.; Zounes, M. C.; Cummins, L. L.; Gonzalez, C.; Cook, P. D. J. Med. Chem. 1993, 36, 831-841. doi:10.1021/jm00059a007

186. Damha, M. J.; Wilds, C. J.; Noronha, A.; Brukner, I.; Borkow, G.; Arion, D.; Parniak, M. A. J. Am. Chem. Soc. 1998, 120, 12976-12977. doi:10.1021/ja982325+

187.Lok, C.-N.; Viazovkina, E.; Min, K.-L.; Nagy, E.; Wilds, C. J.; Damha, M. J.; Parniak, M. A. Biochemistry 2002, 41, 3457-3467. doi:10.1021/bi0115075

188. Kalota, A.; Karabon, L.; Swider, C. R.; Viazovkina, E.; Elzagheid, M.; Damha, M. J.; Gewirtz, A. M. Nucleic Acids Res. 2006, 34, 451-461. doi:10.1093/nar/gkj455

189.Berger, I.; Tereshko, V.; Ikeda, H.; Marquez, V. E.; Egli, M. Nucleic Acids Res. 1998, 26, 2473-2480. doi:10.1093/nar/26.10.2473

190.Li, F.; Sarkhel, S.; Wilds, C. J.; Wawrzak, Z.; Prakash, T. P.; Manoharan, M.; Egli, M. Biochemistry 2006, 45, 4141-4152. doi:10.1021/bi052322r

191.Trempe, J.-F.; Wilds, C. J.; Denisov, A. Y.; Pon, R. T.; Damha, M. J.; Gehring, K. J. Am. Chem. Soc. 2001, 123, 4896-4903. doi:10.1021/ja003859p

192.Denisov, A. Yu.; Noronha, A. M.; Wilds, C. J.; Trempe, J.-F.; Pon, R. T.; Gehring, K.; Damha, M. J. Nucleic Acids Res. 2001, 29, 4284-4293. doi:10.1093/nar/29.21.4284 
193.Salazar, M.; Fedoroff, O. Y.; Miller, J. M.; Ribeiro, N. S.; Reid, B. R. Biochemistry 1993, 32, 4207-4215. doi:10.1021/bi00067a007

194.Fedoroff, O. Y.; Salazar, M.; Reid, B. R. J. Mol. Biol. 1993, 233 , 509-523. doi:10.1006/jmbi.1993.1528

195.Watts, J. K.; Martín-Pintado, N.; Gómez-Pinto, I.; Schwartzentruber, J.; Portella, G.; Orozco, M.; González, C.; Damha, M. J. Nucleic Acids Res. 2010, 38, 2498-2511. doi:10.1093/nar/gkp1225

196. Martín-Pintado, N.; Yahyaee-Anzahaee, M.; Campos-Olivas, R.; Noronha, A. M.; Wilds, C. J.; Damha, M. J.; González, C. Nucleic Acids Res. 2012, 40, 9329-9339. doi:10.1093/nar/gks672

197. Martin-Pintado, N.; Deleavey, G. F.; Portella, G.; Campos-Olivas, R.; Orozco, M.; Damha, M. J.; González, C. Angew. Chem., Int. Ed. 2013, 52, 12065-12068. doi:10.1002/anie.201305710

198.Dowler, T.; Bergeron, D.; Tedeschi, A.-L.; Paquet, L.; Ferrari, N.; Damha, M. J. Nucleic Acids Res. 2006, 34, 1669-1675. doi:10.1093/nar/gkl033

199.Kel'in, A. V.; Zlatev, I.; Harp, J.; Jayaraman, M.; Bisbe, A.; O'Shea, J.; Taneja, N.; Manoharan, R. M.; Khan, S.; Charisse, K.; Maier, M. A.; Egli, M.; Rajeev, K. G.; Manoharan, M. J. Org. Chem. 2016, 81, 2261-2279. doi:10.1021/acs.joc.5b02375

200.Harp, J. M.; Guenther, D. C.; Bisbe, A.; Perkins, L.; Matsuda, S.; Bommineni, G. R.; Zlatev, I.; Foster, D. J.; Taneja, N.; Charisse, K.; Maier, M. A.; Rajeev, K. G.; Manoharan, M.; Egli, M. Nucleic Acids Res. 2018, 46, 8090-8104. doi:10.1093/nar/gky703

201.Liboska, R.; Snášel, J.; Barvík, I.; Buděšínský, M.; Pohl, R.; Točík, Z.; Páv, O.; Rejman, D.; Novák, P.; Rosenberg, I. Org. Biomol. Chem. 2011, 9, 8261-8267. doi:10.1039/c1ob06148h

202.Petrová, M.; Páv, O.; Buděšínský, M.; Zborníková, E.; Novák, P.; Rosenbergová, Š.; Pačes, O.; Liboska, R.; Dvořáková, I.; Šimák, O.; Rosenberg, I. Org. Lett. 2015, 17, 3426-3429. doi:10.1021/acs.orglett.5b01430

203.Jenkins, I. D.; Verheyden, J. P. H.; Moffatt, J. G. J. Am. Chem. Soc. 1976, 98, 3346-3357. doi:10.1021/ja00427a049

204.Owen, G. R.; Verheyden, J. P. H.; Moffatt, J. G. J. Org. Chem. 1976 41, 3010-3017. doi:10.1021/jo00880a018

205. Thomas, S. O.; Singleton, V. L.; Lowery, J. A.; Sharpe, R. W.; Pruess, L. M.; Porter, J. N.; Mowat, J. H.; Bohonos, N. Antibiot. Annu. 1956, 716-721.

206. Martínez-Montero, S.; Deleavey, G. F.; Kulkarni, A.; Martín-Pintado, N.; Lindovska, P.; Thomson, M.; González, C.; Götte, M.; Damha, M. J. J. Org. Chem. 2014, 79, 5627-5635. doi:10.1021/j0500794v

207. Martínez-Montero, S.; Deleavey, G. F.; Martín-Pintado, N.; Fakhoury, J. F.; González, C.; Damha, M. J. ACS Chem. Biol. 2015, 10, 2016-2023. doi:10.1021/acschembio.5b00218

208.Martínez-Montero, S.; Deleavey, G. F.; Dierker-Viik, A.; Lindovska, P.; Ilina, T.; Portella, G.; Orozco, M.; Parniak, M. A.; González, C.; Damha, M. J. J. Org. Chem. 2015, 80, 3083-3091. doi:10.1021/j0502948t

209. Malek-Adamian, E.; Patrascu, M. B.; Jana, S. K.; Martínez-Montero, S.; Moitessier, N.; Damha, M. J. J. Org. Chem. 2018, 83, 9839-9849. doi:10.1021/acs.joc.8b01329

210. Malek-Adamian, E.; Guenther, D. C.; Matsuda, S.; Martínez-Montero, S.; Zlatev, I.; Harp, J.; Burai Patrascu, M.; Foster, D. J.; Fakhoury, J.; Perkins, L.; Moitessier, N.; Manoharan, R. M.; Taneja, N.; Bisbe, A.; Charisse, K.; Maier, M.; Rajeev, K. G.; Egli, M.; Manoharan, M.; Damha, M. J. J. Am. Chem. Soc. 2017, 139, 14542-14555. doi:10.1021/jacs.7b07582
211.Li, Q.; Chen, J.; Trajkovski, M.; Zhou, Y.; Fan, C.; Lu, K.; Tang, P.; Su, X.; Plavec, J.; Xi, Z.; Zhou, C. J. Am. Chem. Soc. 2020, 142, 4739-4748. doi:10.1021/jacs.9b13207

212.Gore, K. R.; Nawale, G. N.; Harikrishna, S.; Chittoor, V. G.; Pandey, S. K.; Höbartner, C.; Patankar, S.; Pradeepkumar, P. I. J. Org. Chem. 2012, 77, 3233-3245. doi:10.1021/jo202666m

213. Koizumi, K.; Maeda, Y.; Kano, T.; Yoshida, H.; Sakamoto, T.; Yamagishi, K.; Ueno, Y. Bioorg. Med. Chem. 2018, 26, 3521-3534. doi:10.1016/j.bmc.2018.05.025

214. Kano, T.; Katsuragi, Y.; Maeda, Y.; Ueno, Y. Bioorg. Med. Chem. 2018, 26, 4574-4582. doi:10.1016/j.bmc.2018.08.001

215. Nawale, G. N.; Bahadorikhalili, S.; Sengupta, P.; Kadekar, S.; Chatterjee, S.; Varghese, O. P. Chem. Commun. 2019, 55, 9112-9115. doi:10.1039/c9cc04141a

216. Herdewijn, P. Chem. Biodiversity 2010, 7, 1-59. doi:10.1002/cbdv.200900185

217. Aerschot Van, A.; Verheggen, I.; Hendrix, C.; Herdewijn, P. Angew. Chem., Int. Ed. Engl. 1995, 34, 1338-1339. doi:10.1002/anie.199513381

218. Hendrix, C.; Rosemeyer, H.; Verheggen, I.; Van Aerschot, A.; Seela, F.; Herdewijn, P. Chem. - Eur. J. 1997, 3, 110-120. doi:10.1002/chem.19970030118

219. Hossain, N.; Wroblowski, B.; Van Aerschot, A.; Rozenski, J.; De Bruyn, A.; Herdewijn, P. J. Org. Chem. 1998, 63, 1574-1582. doi:10.1021/j09718511

220. Allart, B.; Khan, K.; Rosemeyer, H.; Schepers, G.; Hendrix, C.; Rothenbacher, K.; Seela, F.; Van Aerschot, A.; Herdewijn, P. Chem. - Eur. J. 1999, 5, 2424-2431. doi:10.1002/(sici)1521-3765(19990802)5:8<2424::aid-chem2424>3.0. $\mathrm{co} ; 2-\mathrm{w}$

221. Egli, M.; Pallan, P. S.; Allerson, C. R.; Prakash, T. P.; Berdeja, A.; Yu, J.; Lee, S.; Watt, A.; Gaus, H.; Bhat, B.; Swayze, E. E.; Seth, P. P. J. Am. Chem. Soc. 2011, 133, 16642-16649. doi:10.1021/ja207086x

222. Winter, H. D.; Lescrinier, E.; Aerschot, A. V.; Herdewijn, P. J. Am. Chem. Soc. 1998, 120, 5381-5394. doi:10.1021/ja973721f

223. Vandermeeren, M.; Préveral, S.; Janssens, S.; Geysen, J.; Saison-Behmoaras, E.; Van Aerschot, A.; Herdewijn, P. Biochem. Pharmacol. 2000, 59, 655-663. doi:10.1016/s0006-2952(99)00367-6

224. Allerson, C. R.; Sioufi, N.; Jarres, R.; Prakash, T. P.; Naik, N.; Berdeja, A.; Wanders, L.; Griffey, R. H.; Swayze, E. E.; Bhat, B. J. Med. Chem. 2005, 48, 901-904. doi:10.1021/jm049167j

225.Davis, S.; Propp, S.; Freier, S. M.; Jones, L. E.; Serra, M. J.; Kinberger, G.; Bhat, B.; Swayze, E. E.; Bennett, C. F.; Esau, C. Nucleic Acids Res. 2009, 37, 70-77. doi:10.1093/nar/gkn904

226. Prakash, T. P.; Yu, J.; Kinberger, G. A.; Low, A.; Jackson, M.; Rigo, F.; Swayze, E. E.; Seth, P. P. Bioorg. Med. Chem. Lett. 2018, 28, 3774-3779. doi:10.1016/j.bmcl.2018.10.011

227.Pallan, P. S.; Yu, J.; Allerson, C. R.; Swayze, E. E.; Seth, P.; Egli, M. Biochemistry 2012, 51, 7-9. doi:10.1021/bi201810r

228. Seth, P. P.; Allerson, C. R.; Østergaard, M. E.; Swayze, E. E. Bioorg. Med. Chem. Lett. 2012, 22, 296-299. doi:10.1016/j.bmcl.2011.11.012

229.De, S.; Jabgunde, A. M.; Patil, R. S.; De Jonghe, S.; Beigelman, L.; Herdewijn, P. J. Org. Chem. 2018, 83, 15155-15169. doi:10.1021/acs.joc.8b02444

230.Jabgunde, A. M.; Patil, R. S.; De, S.; Lescrinier, E.; De Jonghe, S.; Beigelman, L.; Herdewijn, P. Tetrahedron 2019, 75, 1107-1114. doi:10.1016/j.tet.2019.01.026 
231.Schweitzer, B. A.; Kool, E. T. J. Org. Chem. 1994, 59, 7238-7242. doi:10.1021/jo00103a013

232.Moran, S.; Ren, R. X.-F.; Rumney, S., IV; Kool, E. T. J. Am. Chem. Soc. 1997, 119, 2056-2057. doi:10.1021/ja963718g 233. Khakshoor, O.; Wheeler, S. E.; Houk, K. N.; Kool, E. T. J. Am. Chem. Soc. 2012, 134, 3154-3163. doi:10.1021/ja210475a 234. Kellinger, M. W.; Ulrich, S.; Chong, J.; Kool, E. T.; Wang, D.

J. Am. Chem. Soc. 2012, 134, 8231-8240. doi:10.1021/ja302077d

235.Xia, J.; Noronha, A.; Toudjarska, I.; Li, F.; Akinc, A.; Braich, R.; Frank-Kamenetsky, M.; Rajeev, K. G.; Egli, M.; Manoharan, M. ACS Chem. Biol. 2006, 1, 176-183. doi:10.1021/cb600063p

236. Ulrich, S.; Kool, E. T. Biochemistry 2011, 50, 10343-10349. doi:10.1021/bi2011465

237.Li, F.; Pallan, P. S.; Maier, M. A.; Rajeev, K. G.; Mathieu, S. L.; Kreutz, C.; Fan, Y.; Sanghvi, J.; Micura, R.; Rozners, E.; Manoharan, M.; Egli, M. Nucleic Acids Res. 2007, 35, 6424-6438. doi:10.1093/nar/gkm664

238. Egli, M.; Pallan, P. S. Annu. Rev. Biophys. Biomol. Struct. 2007, 36, 281-305. doi:10.1146/annurev.biophys.36.040306.132556

239. Egli, M. Acc. Chem. Res. 2012, 45, 1237-1246. doi:10.1021/ar200303k

240. Pallan, P. S.; Egli, M. J. Am. Chem. Soc. 2009, 131, 12548-12549. doi:10.1021/ja905739j

\section{License and Terms}

This is an Open Access article under the terms of the Creative Commons Attribution License (https://creativecommons.org/licenses/by/4.0). Please note that the reuse, redistribution and reproduction in particular requires that the author(s) and source are credited and that individual graphics may be subject to special legal provisions.

The license is subject to the Beilstein Journal of Organic Chemistry terms and conditions:

(https://www.beilstein-journals.org/bjoc/terms)

The definitive version of this article is the electronic one which can be found at:

https://doi.org/10.3762/bjoc.17.76 